\title{
OS MODELOS DE REFORMA SANITÁRIA DOS ANOS 80: UMA ANÁLISE CRÍTICA*
}

Celia Almeida* *

\begin{abstract}
Resumo: Este artigo analisa os principais modelos de reforma sanitária nos paises centrais, nos anos 80 , dissecando o corpo de idéias que informou as estratégias de mudança e os elementos constitutivos de uma nova agenda pós-welfare também para o setor saúde. Assume como premissas que a crise fiscal do Estado, a partir de meados dos 70 , e a hegemonia neoliberal da década contribuiram para a formulação de um diagnóstico setorial comum e de prescrições que se difundiram como alternativas para o controle do crescimento do gasto sanitário e para o funcionamento dos sistemas de serviços de saúde mais eficiente e voltado para o consumidor. A partir da experiência norte-americana reintroduziu-se a idéia de competição no setor saúde, que teve várias releituras e aplicações no contexto europeu. Nesse processo produziram-se alguns modelos considerados paradigmáticos para a necessária reestruturação dos serviços de saúde, vinculados às exigências macroeconômicas de contenção de custos e de controle de crescimento do déficit público. A avaliação comparativa dessas políticas, nos países centrais, constata que as opções nacionais variaram muito e que existe uma grande distância entre o discurso ideológico e as políticas implementadas, evidenciandose uma atuação estatal mais reguladora e centralizada, além de uma clara tensão entre os controles político e financeiro e a operacionalização dos mecanismos de competição nos sistemas de saúde.
\end{abstract}

Palavras-chave: reforma sanitária contemporânea; novos modelos gerenciais; mercado interno

\footnotetext{
* Grande parte do conteúdo deste artigo é uma sintese do Capítulo II - "Os Modelos de Reforma Sanitária dos Anos 80" - e algumas das principais conclusões da Tese de Doutorado - As Reformas Sanitárias dos Anos 80: Crise ou Transição? - apresentada pela autora à Escola Nacional de Saúde Pública (ENSP)/Fundação Oswaldo Cruz (FIOCRUZ), em julho de 1995, citada na bibliografia.

** Médica, Mestre em Medicina Social, PhD em Saúde Pública, Pesquisadora-Titular e Docente do Departamento de Administração e Planejamento em Saúde da Escola Nacional de Saúde Pública (ENSP)/Fundação Oswaldo Cruz (FIOCRUZ), Rio de Janeiro, Brasil.
} 
“Em suma, não se pode observar uma onda sem levar em conta os aspectos complexos que concorrem para formá-la e aqueles também complexos a que essa dá ensejo...".

$\cdots$

"Acresce que o refluxo de cada onda também possui uma força que se opõe às ondas supervenientes. $E$ se concentrarmos a atenção nesses impulsos retroativos vai nos parecer que o verdadeiro movimento é aquele que parte da praia em direção ao largo". (ITALO CALVINO, "Palomar na Praia - Leitura de uma onda". Palomar, Companhia das Letras).

\section{INTRODUÇÃO}

A intensa mobilização política e social dos anos 60 e 70 estimulou, também no campo da saúde, uma crítica contundente e questionadora de todos os fundamentos básicos dos sistemas de serviços de saúde, sobretudo de assistência médica. Com a crise fiscal do Estado, a partir de meados dos 70 , esse arsenal alimentou a formulação de um diagnóstico comum e das prescrições neoconsenvadoras, configurando uma agenda pós-welfare também para a saúde, que, na década seguinte, orientou as reformas sanitárias.

As reformas sanitárias são analisadas neste artigo como parte da resposta liberalconservadora (ou neoliberal) à crise econômica dos anos 73-75 e como desdobramentos de um modelo formulado nos EUA no final dos anos 70 - a managed competition ou "competição administrada" - que, na década de 80 , teve várias releituras e utilizações no contexto europeu (ALMEIDA, 1995) ${ }^{1}$.

As justificativas reformistas dos sistemas de saúde, na essência, têm a mesma base teórica formulada para decretar o fim do welfare state: 
- o Estado de Bem-Estar Social se havia "sobrecarregado" e as democracias ocidentais se haviam tornado "ingovernáveis", na opinião de seus críticos, além de que o crescente papel do Estado na distribuição de serviços e rendas havia despertado expectativas irreais;

desfazendo-se de algumas funções, o Estado poderia aliviar-se de certas demandas e dos conflitos gerados por elas; além disso - diziam os neoconservadores - 0 governo era intrinsecamente incompetente para algumas tarefas, uma vez que os requisitos políticos se antagonizavam com os ditames da eficiência e os instrumentos da politica pública eram pouco sensiveis às preferências individuais e às condições locais; e

- o governo criara uma "nova classe" (os burocratas e funcionários do Estado) interessada em "mais intervenção" governamental, financiada pormaiores impostos, que se constituíam em pesada carga para os consumidores e a economia privada, asfixiando a inovação e o investimento.

Afirmava-se que os ganhos do welfare com a busca da eqüidade seriam menores do que as perdas de eficiência que a intervenção estatal produziu; que a "inerente ineficiência do governo" (em comparação com o setor privado) teria estimulado mais disfunção, ao tentar corrigir as falhas do mercado; e que o aumento da intervenção do Estado na área social teria provocado a desmotivação e "a manutenção da dependência dos indivíduos". Isto porque a provisão pública baseava-se em "julgamentos morais" sobre quem tinha direito de receber benefícios e/ou serviços e necessidades, decisão esta sempre mediada pelos prestadores e pelos grupos de interesse, sem vinculação com as demandas reais dos "consumidores" e com os recursos disponíveis para tal (Economic Policy, 1988, apud BENNETT, 1990:22)².

Nos anos 80 não mais se fala em crise sanitária, mas em crise dos sistemas de serviços de saúde. Na maioria da literatura que se dedicou a discutir essa crise, observa-se uma grande homogeneidade nas avaliações (com argumentos basicamente econômicos, independentemente da filiação ideológica do autor) e a constatação de uma confluência de problemas semelhantes enfrentados por todos os sistemas sanitái ios nos diversos países ${ }^{3}$.

O controle do déficit público e do gasto sanitário está subjacente a todas as reformas, vinculadas a exigências macroeconômicas, incorporando as mesmas premissas de "menos 
Estado", privatização, flexibilização e desregulação. Os eixos em torno dos quais se articulam essas propostas são a restrição da autonomia profissional; a reestruturação do mix público/ privado; e a descentralização, para os níveis subnacionais e para o setor privado.

A partir da experiência americana reatualiza-se a idéia de competição no setor sanitário, reinterpretada nas propostas européias, que adotam como paradigma a "competição administrada" (managed competition). O "Mercado Interno" inglês, proposto pelo Working for Patients em 1989, é a versão mais acabada dessa difusão, que inspirou várias outras reformas, entre as quais se destacam a "Competição Pública", na Suécia (desde o final dos anos 80); o Relatório Dekker, na Holanda (1987); as medidas concertadas de contenção de custos na Alemanha (desde os meados dos 80 ); e a reforma do sistema sanitário na Nova Zelândia $(1993)^{4}$. Esse mesmo referencial tem influenciado tảmbém as propostas de "reformas da reforma" na Itália (1992) e na Espanha (1991).

Este artigo propõe-se a analisar criticamente os principais e mais polêmicos modelos de reforma sanitária dos anos 80 . Na primeira parte sintetizo o diagnóstico da problemática do setor formulado na perspectiva da reforma neoliberal e os principais elementos constitutivos de uma "mudança de paradigma" reorientadora da nova agenda para o setor. A seguir, discuto alguns dos mecanismos e modelos de reforma propostos e/ou implementados nos países centrais. E por fim apresento uma conclusão crítica sobre esses desenvolvimentos.

\section{O DIAGNÓSTICO NEOLIBERAL DA CRISE DOS SERVIÇOS DE SAÚDE}

No campo sanitário, sobretudo no que concerne aos serviços de saúde e assistência médica, a retórica ideológica neoconservadora estimulou a formulação de um diagnóstico setorial que apontava para a necessidade de determinadas mudanças. Utilizando a extensa gama de críticas, de diversos matizes, presentes no debate sanitário desde meados dos 60 , 
o novo discurso, que passou a ser hegemônico nos 80 , defendia a aceitação pragmática da realidade da mudança nas condições econômicas, pregavam o não compromisso com a expansão dos serviços de saúde e repudiavam a intervenção governamental.

Centrada em argumentos basicamente econômicos, essa avaliação, de inspiração neoliberal, desnudava vários problemas de fato presentes no campo setorial, mas, na retórica reformista da década, pretendia mudar as fronteiras da atuação do Estado. Assim, enfatizava que:

- a inexorabilidade da escassez de recursos não permitia a manutenção dos padrões anteriores de gasto sanitário e das formas de estruturação dos serviços de assistência médica adotadas no pós-guerras, pela exacerbação do déficit público que provocavam, sobretudo com a crise fiscal do Estado. Isto é, questionavam-se o predomínio dos fundos públicos no financiamento da prestação da atenção médica à população e o investimento tecnológico contínuo e frenético, característico do desenvolvimento dos serviços de saúde a partir da segunda metade deste século. Apregoava-se tanto a restrição da oferta de serviços de saúde quanto a descentralização, para níveis subnacionais e para o setor privado;

- a ineficiência dos sistemas sanitários, pelo não comprometimento dos agenciadores do gasto - isto é, os profissionais - com os custos dos serviços, impedia a identificação de responsabilidades no uso dos recursos, exigindo medidas de restrição da autonomia profissional e o deslocamento do poder monopolístico dos prestadores de serviços, com a introdução de mecanismos competitivos e de mudanças gerenciais típicas do setor privado. Ou seja, o médico foi o alvo central dessa crítica;

- a desvinculação entre o investimento setorial e os resultados efetivos em termos de melhoria da saúde da população indicava desperdício e necessidade de redirecionamento de prioridades. Isto é, o Estado não podia continuar arcando com a responsabilidade de garantia de acesso à assistência médica a toda a população, inclusive diminuindo seu papel como empregador e/ou desregulando os contratos do funcionalismo público; e a relação entre niveis de atenção devia ser repensada (leia-se, atenção primária versus atendimento hospitalar);

- a remoção das barreiras de preço para o consumo de serviços de saúde remetia sempre a excesso de demandas (tanto no caso do financiamento estatal quanto no do financiamento pri /ado), que devia ser controlado (tanto pelo goverrn quanto pelas empresas e seguradoras), através da participação financeira do usuário ou de coberturas parciais. Ou seja, era necessário reprimir a demanda de serviços, incentivando no usuário a consciência dos custos; e, por fim, 
- o desempenho insatisfatório dos serviços frente às exigências do consumidor frustrava a sua liberdade de escolha e a satisfação de suas necessidades. Portanto, era preciso abrir o mercado de serviços de saúde para a escolha do consumidor e, através da competição entre serviços, eliminar os ineficientes, fundamentalmente os do setor público.

À primeira vista, esse pacote de diagnósticos e de prescrições parecia pertinente e necessário e angariou muitos simpatizantes, sendo difícil analisá-lo de forma distanciada do senso comum, uma vez que seus defensores o vendiam como uma já tardia e necessária modernização gerencial dos serviços sanitários, justificada pela retórica do desempenho e da qualidade da atenção, designadas para acabar com as ineficiências burocráticas e a rigidez profissional acumuladas durante os períodos de expansão dos anos 60 e 70.

Configurou-se assim um extenso elenco de medidas e procedimentos que formalizaram uma "agenda de reforma pós-welfare" (BENNETT, 1990) também para a área sanitária, inicialmente nos países centrais, mas que se expandiu até a periferia, questionando os fundamentos básicos que haviam estruturado os sistemas de saúde até então, colocando sob suspeita a universalização e a eqüidade, onde elas existem, e pregando a impossibilidade de alcançá-las, onde esses objetivos ainda eram uma aspiração.

Essa nova agenda de reforma dos serviços de saúde estava centrada numa "mudança de paradigma" da intervenção estatal em campo social, cujos elementos centrais seriam $(O E C D, 1987)$ :

1. Resposta do Estado ao consumidor: pelo discurso político-ideológico, a questão estava posta como a busca de uma melhor relação entre os consumidores dos serviços e o Estado que os proporcionava. De fato, a mudança crucial de paradigma foi na direção de tentar transformar o compromisso governamental - de garantia do direito de acesso aos serviços para todos os cidadãos - em políticas que se baseavam num conceito de demanda expressa segundo as preferências do consumidor e que levavam em consideração a questão dos custos. Isto significava mudança da ênfase na produção 
direta de serviços pelo governo, para "provisão em um ambiente regulatório apropriado", que, teoricamente, estimularia a ação individual, proporcionaria equilíbrio nas respostas do mercado privado e nas atividades de organizações não-lucrativas e desencadearia o estreitamento das relações entre os consumidores, os prestadores de serviços e os níveis governamentais.

2. Inovações nas formas de organização da distribuição de serviços: a concepção dos serviços sociais como bens públicos passou a ser desafiada como o guia de ação para a provisão de serviços. Argumentava-se que o governo não era o único que podia organizar a provisão coletiva: a ação de grupos de pessoas e/ou empresas poderia fornecer meios válidos e mais eficientes para superar os problemas colocados pelos free riders ${ }^{5}$, estimulando-se assim as ações voluntárias e comunitárias, como sugere, por exemplo, a teoria da public-choice. Ou seja, o governo não seria o provedor de serviços por excelência e, da mesma forma, o financiamento desses serviços não deve necessariamente provir de impostos gerais. Entretanto, o Estado deve reter importante papel regulador, conferindo o desempenho do setor e estabelecendo o ambiente geral do processo decisório. $O$ resultado dessa revisão foi a abertura de uma nova agenda de discussão, na busca de meios mais efetivos de distribuição de serviços como alternativa ou suplementação da provisão estatal;

3. Financiamento e recuperação de custos: o financiamento, tanto da infra-estrutura quanto da melhoria dos serviços, por outros meios que não os orçamentos gerais (isto é, a arrecadação fiscal) seria mais efetivo na sustentação de uma posição financeira equilibrada entre os níveis federal/central e estadual/local. Isto estimularia, segundo seus defensores, maiores inovações na perspectiva de recuperação de custos, ao invés de introdução de novos impostos ou taxas específicas. Ao mesmo tempo, recomendava-se o redirecionamento dos sistemas tributários, central e local, e do sistema de transferências entre níveis, numa perspectiva de custo-benefício, isto é, impostos-benefícios. 0 financiamento de serviços, portanto, mudaria em cada nível segundo uma estreita relação entre custos e serviços prestados ou recebidos, de acordo com os princípios de trocas de mercado. $O$ debate sugeria que não era mais possível prover tudo a todos e, se o objetivo 
central era recuperar os mecanismos de mercado para obter uma melhor relação entre demanda e oferta através dos custos, então os impostos não seriam o melhor meio de financiamento. Obviamente nem todas as rendas poderiam ser submetidas nessa direção, uma vez que a retenção de oportunidades redistributivas continuava a ser uma área central de qualquer governo, mas a tendência geral dessas propostas caminhava para a permanência do Estado apenas em atuações focais e seletivas para grupos específicos (por exemplo, populações com níveis absolutos de pobreza, deficientes, aposentados etc).

4. Reformas gerenciais (ou responsabilização interna): a melhoria na eficiência e maior responsabilidade com o consumidor deveria ser buscada nas instituições estatais através de mudanças na estrutura gerencial. Os objetivos centrais eram: a) a busca te meios para responder à demanda real e não às decisões programáticas e burocráticas sobre $c$ que as pessoas necessitariam ou a que deveriam ter acesso; b) a revisão dc Jesempenho dos funcionários públicos, que deveriam proporcionar serviços efetivos e eficientes e não atuar segundo decisões e demandas de sindicatos ou corporações de profissionais; c) a restrição e o redimensionamento do emprego público, uma vez que os serviços governamentais deveriam responder às demandas da população e não constituir um meio clientelista de troca política; e d) o estímulo à flexibilização (leia-se privatização) dos meios de provisão de serviços, com vistas a aumentar a eficiência, superando as pesadas e monolíticas instituições estatais. Em resumo, o objetivo maior seria estabelecer mecanismos pelos quais as decisões burocráticas governamentais fossem substituídas por uma estrutura gerencial mais leve, que permitisse respostas demanda/oferta semelhantes àquelas presentes no mercado. A indução de tais respostas na estrutura gerencial estatal seria tentada através da introdução no setor público de conceitos de gerenciamento e contabilidade usuais do setor privado.

5. Reinterpretação da representação (ou responsabilização externa): os processos usuais de representação política (tanto os procedimentos democráticos gerais, quanto os

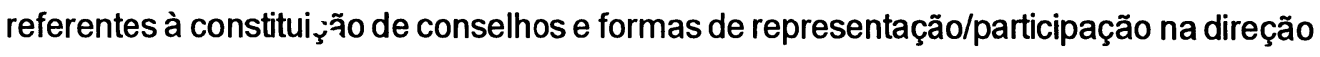


dos serviços), foram questionados, enfatizando-se a desilusão com os poucos resultados com esses procedimentos e propondo-se substituir as escolhas políticas ou burocráticas pela escolha do consumidor. A vinculação entre a cobrança política e a distribuição de serviços também foi posta em dúvida nessa nova agenda e, embora se aceitasse que o locus político jogasse um papel fundamental, alegava-se que não constituía o melhor espaço para a tomada de decisões, sobretudo nos assuntos técnicos e operacionais. 0 conflito maior, portanto, estaria na tentativa, frustrada, de resolução de questões econômicas e de eficiência competitiva através de noções políticas e sociológicas de representação no contexto dos governos locais.

Evidentemente, aumentar a responsabilidade com o consumidor, melhorar a organização da distribuição de senviços, inovar no financiamento e na recuperação dos custos, implementar reformas gerenciais e reinterpretar as representações podem ser metas de qualquer governo, independentemente da estrutura ideológica. Entretanto, o objetivo maior por detrás dessas reformas nos anos 1980 foi uma ampla agenda política para mudar as fronteiras do Estado, pois - justificava-se - havia necessidade de "menos governo".

As conseqüências dessa estratégia homogeneizante de reprivatização têm sido inúmeras e talvez inadvertidas por seus mentores. No que toca à assistência médica e aos sistemas sanitários, o movimento de reformas, que a partir de então se generalizou pelo mundo, produziu alguns modelos que passaram a ser difundidos como novos paradigmas para a reestruturação dos sistemas de serviços de saúde.

\section{CRISE, CONTENÇÃO E REFORMA}

Com a crise econômica e sanitária dos meados dos 70 , a preocupação com a saúde em praticamente todos os países centrais mudou de significado e, no debate crítico que se seguiu à questão dos altos custos da assistência médica, ocupou o centro da agenda pública setorial. Os serviços sanitários absorviam em média 7,5\% do PIB (mais de $12 \%$ nos EUA) e o montante público desse gasto totalizava em muitos países cerca de $76 \%$ (5,5\% do 
PIB), além de que a inflação médica manteve-se mais alta que os valores da economia em geral, na maioria dos países nas últimas décadas (SCHIEBER \& POULLIER, 1990:24). Tornouse consenso, por toda parte, que tais somas deveriam ser gerenciadas e a inflação setorial necessariamente contida, seguindo as prescrições das políticas de ajuste macroeconômico então em curso.

A primeira resposta a esses custos crescentes, em praticamente todos os países, foi uma série de medidas para contenção; os métodos variaram segundo a organização e financiamento dos serviços de saúde nos diversos países. As políticas restritivas implementadas foram dirigidas para operar tanto sobre a demanda quanto sobre a oferta, em sistemas financiados através de orçamentos públicos ou de contribuição para seguro-cioença compulsório. Alguns autores as consideraram estratégias racior.alizadoras, enquanto outros as analisaram como formas de privatização. Os desafios foram muito maiores, porém, com piores resultados, nos sistemas em que os seguradores prestavam serviços através da contratação de profissionais e serviços privados independentes, tal como no sistema norteamericano.

No caso da limitação da demanda, nos sistemas nacionais de saúde tomou a forma em geral de co-participação financeira do usuário (cost-sharing) e de concessão de deduções de imposto de renda para aqueles que utilizassem o setor privado. Outros mecanismos foram utilizados também no sistema de seguros, tais como restringir reembolsos, limitar o escopo da atenção, exigir autorização para determinadas intervenções. Também se incluíram nesta categoria ampla gama de medidas preventivas e de estilo de vida destinadas a diminuir os riscos de saúde e a responsabilizar o indivíduo por sua doença, que, por um lado, envolvem via de regra muito mais do que o setor sanitário e, por outro, levantam discussões éticomorais bastante complexas.

A contenção de custos do lado da oferta, por sua vez, possuía uma variedade muito maior de instrumentos, sobretudo quando utilizados no dimensionamento da força de trabalho 
ou dos investimentos setoriais, ou ainda na contratação de serviços, tendo sido a estratégia mais utilizada por todos os países. Pode ser de curto prazo, tal como imposição de tetos ou controle de preços; ou mais permanentes e estruturais, como a limitação da taxa de emprego no setor público; restrição da expansão ou da construção de hospitais; interferências nos métodos de remuneração dos profissionais; fechamento de serviços, corte de subsídios ou contratos; racionalização do uso dos equipamentos mais caros; imposição de certificados de aprovação ou necessidade para a compra de novas tecnologias; restrição do licenciamento ou entrada de profissionais autorizados a atender pelos seguros. Particularmente efetivas foram as diversas formas de impor limites orçamentários segundo a disponibilidade de caixa, orçamentos gerenciados por programas, definição de quotas para diferentes subsetores ou para o sistema como um todo.

Essas medidas, em diferentes mix, foram amplamente implantadas em quase todos os sistemas de saúde com maior ou menor sucesso, mas de uma maneira geral pode-se dizer que surtiram efeito, sobretudo nos países europeus.

A seguir discutiremos alguns dos mecanismos mais polêmicos que têm sido utilizados em várias propostas de reforma sanitária em muitos países.

\section{Co-participação financeira do usuário (cost-sharing) ou ticket moderador}

Os chamados tickets moderadores são mecanismos de co-participação do paciente no custo dos serviços, justificados para estimular a conscientização do usuário e do profissional sobre os preços dos serviços quando da sua utilização. Foram implementados historicamente por vários sistemas europeus, para medicamentos - praticamente todos os países, exceto Holanda -, tratamentos dentários, óculos, consultas especializadas etc. Podem traduzir-se em uma taxa fixa para cada prescrição ou em uma porcentagem que varia segundo o tipo de prescrição e/ou renda e/ou grupo específico.

Essa estratégia de contenção de gastos vem sendo introduzida em diversos países 
na Europa, desde os anos 70, e à participação do usuário no financiamento da assistência médica no momento da utilização sã̉o atribuídas tanto funções alocativas quanto financeiras (BARILETTI \& ARCANGELI, 1987:106).

No que concerne à alocação de recursos, a introdução dos tickets está relacionada a objetivos racionalizadores das várias formas de assistência sobre as quais eles recaem, tornando positivo o seu custo para o usuário/consumidor. Na intenção dos introdutores dessa política a avaliação do custo marginal em relação ao benefício do senviço (ou "bem público") a consumir deveria levar à eliminação da utilização não necessária ou, de maneira geral, a uma redução da quantidade solicitada. Ou seja, a justificativa reside na necessidade de desencorajar a utilização pelo usuário (ou induzir a escolha do mais barato, como nos medicamentos) e estimular a prescrição mais responsável pelos profissionais, conscientizando ambos, consumidor e profissional, dos custos dos serviços. Os autores lembram, entretanto, que, no caso sanitário, esse mecanismo pode ser menos efetivo pelo seguinte fato: quem decide sobre a utilização de serviços e; conseqüentemente, sobre o gasto, não é o cidadão/ usuário/consumidor que paga o ticket, mas os seus respectivos médicos. Ressaltam ainda que os efeitos do racionamento poderiam ser limitados e condicionados pelas relações de interdependência entre oferta e demanda, além dos problemas de ordem social e pessoal que também interferem nesse processo: o objetivo geral de redução tendencial do consumo desnecessário pode encontrar limites de caráter distributivo, uma vez que a introdução do ticket pode resultar regressiva, seja em termos de renda, seja do status sanitário de grupos particulares, o que acaba por justificar a introdução das isenções ou discriminações favoráveis aos grupos tidos como mais necessitados de tutela estatal.

Quanto aos aspectos financeiros, independentemente das razões expostas acima, os tickets têm sido introduzidics com a perspectiva de diversificar as fontes de entrada de recursos e aumentar a receita e conseqüentemente - argumenta-se - reduzir o gasto público, diminuindo o ônus estatal, ao mesmo tempo aumentando aquele a cargo das famílias, mediante a superposição de cotas de co-participação nos custos, ao invés de exacerbar a carga de arrecadação fiscal ou contributiva (BARILETTI \& ARCANGELI, 1987:106). 
Evidentemente, esse mecanismo age sobre a demanda em nível microeconômico, mas em compensação, em termos macroeconômicos, os tickets revelaram-se, por toda parte, impotentes para o gerenciamento dos gastos sanitários. Isto porque os de baixo valor não têm efeito e os mais caros correm o risco de induzir subconsumo por parte dos pacientes mais necessitados, com agravamento do quadro e maior gasto posterior, além de que contrariam os princípios de justiça social contidos na universalização e no livre acesso aos serviços. Ademais, em termos do aporte de receita, na maioria dos países não ultrapassa os $3 \%$ do orçamento total para a saúde. Ressalva deve ser feita, porém, à utilização feita na Suécia das taxas de co-participação do usuário, numa perspectiva de conter o consumo privado, retirando incentivos dos médicos e dos pacientes para, respectivamente, o exercício e utilização da prática privada.

Apesar destas observações, dois paises utilizaram esse mecanismo mais que outros - os EUA, onde $40 \%$ dos gastos não são reembolsáveis, e a França, com $20 \%$ - e, paradoxalmente são os mesmos que conseguiram menor controle de custos em seus sistemas de serviços de atenção sanitária (MAJNONI D'INTIGNANO, 1991:10). No caso da Itália, por exemplo, a enorme variabilidade da política de tickets durante os anos 80 , aliada à específica forma de estruturação da porta de entrada no sistema, acabou por desencadear mecanismos defensivos e de burla, tanto pelos pacientes quanto pelos profissionais (ALMEIDA, 1995).

Managed Care ou "assistência médica administrada": controle de gastos, regulação (pública e privada) e controle da utilização

A "assistência médica administrada" (ou managed care) foi formulada inicialmente a partir da crença no poder da organização e da regulação privada para influenciar os padrões de prestação de serviços centrados no mercado privado, independente do governo, e a preços acessiveis para a população. Originada nos EUA, no período entre guerras, através de iniciativas empresariais, das quais a experiência da Kaiser é a mais expressiva ${ }^{6}$, foi reatualizada nos 
anos 70 , quando o governo Nixon institucionalizou a assistência médica administrada como política governamental. O managed care desenvolveu-se de forma espetacular nos anos 80 , quando o seguro-saúde de pré-pagamento e o próprio governo, pressionados pelos altos custos da assistência médica e pela persistência da inflação setorial sempre acima da inflação geral, escolheram os planos de managed care como a alternativa que produziria maior possibilidade de controle/contenção de custos.

Esses planos propõem-se a integrar a prestação e o financiamento de serviços assistenciais e conter os custos através de medidas reguladoras da relação médico-paciente. Em outras palavras, pelo lado dos profissionais, os limites estão dados por interferência indireta na autonomia das decisões clínicas, através de incentivos e/ou normas negociadas que induzem os médicos a prescreverem apenas os serviços "necessários". O pré-pagamento de pacotes assistenciais pressupõe o risco de que os custos reais superem as estimativas feitas quando da contratação dos serviços em bloco. Pelo lado do paciente, a regulação se dá através da restrição das opções de escolha do profissional ou do serviço, com incentivos ou condicionantes destinados a induzir o segurado a utilizar os médicos/serviços contratados pelo plano ou selecionados como "preferenciais".

De maneira geral, as definições da assistência médica administrada a caracterizam como um sistema voltado fundamentalmente para o controle da utilização de serviços, que abrange tanto o lado da oferta quanto o da demanda, integrando os seguintes aspectos:

1. contratos com profissionais e serviços selecionados, para a prestação integral da atenção médica a membros de planos de seguro, usualmente mediante o pagamento de um montante fixo anual ou mensal;

2. formas de controle da utilização e da qualidade da atenção pré-fixadas e aceitas pelos prestadores;

3. incentivos financeiros para os pacientes, com a finalidade de induzir a utilização dos prestadores associados aos planos e/ou preferenciais;

4. premissa de co-responsabilização dos médicos nos riscos financeiros da atenção, 
alterando fundamentalmente o seu papel como agente da demanda (em "nome do melhor para o cliente"), balanceando as necessidades do paciente com as de controle de custos, uma vez que os pagamentos são globais e não por unidade de serviço;

5. aceitação pelos médicos e serviços de menores preços e maiores controles sobre sua autonomia técnica e financeira, em troca de um fluxo permanente e garantido de pacientes.

Na sua origem, os planos de pré-pagamento nos EUA sofreram ferrenha oposição da corporação médica e foram apoiados pelos movimentos trabalhistas e de consumidores, tanto por serem considerados uma forma mais solidária de assistência ("os saudáveis subsidiariam os doentes", uma vez que os preços são os mesmos para todos os membros), quanto por serem mais passiveis de controles sobre a atividade profissional.

Essa forma de assistência médica não havia conseguido firmar-se nos EUA, mantendo-se num plano secundário por décadas, até o início dos anos 70 , quando o governo Nixon se apropriou e redefiniu a prática de grupo de pré-pagamento, cunhando o nome Health Maintenance Organizations-HMOs (criadas em 1973, através do HMOs Act), como uma alternativa política que a um só tempo preservaria a assistência médica empresarial e possibilitaria a diminuição da taxa de crescimento do gasto sanitário. Em outras palavras, argumentava-se que a assistência administrada encorajaria a eficiência, atraindo mais membros para aqueles planos que oferecessem padrões mais baratos e de melhor qualidade, ao mesmo tempo em que favoreceria a contenção de custos e diminuiria o gasto sanitário.

Mesmo assim, apenas na década seguinte, nos anos 80 , a montagem de novas alianças em torno da questão dos custos da assistência médica norte-americana possibilitou um grande desenvolvimento dessas práticas. Pelas mãos do empresariado (empregadores, que pagam a maior parte desses gastos), aliados às seguradoras comerciais (assustadas com os custos das indenizações) e aos empresários médicos (associados aos planos de saúde), a proposta conservadora tomou fôlego, na perspectiva tanto de contenção de custos, quanto de preservar a hegemonia no sistema de saúde dos prestadores privados e o controle sobre o sistema dos pagadores privados (MILLER \& LUFT, 1991; IGLEHART, 1992B,C; IMERSHEIN et al., 1992). 
O poder de compra das coalizões empresariais (não sanitárias) serviu como catalisador desse processo, mas contou também com a colaboração dos prestadores de serviços, dispostos a se submeter a controles de qualidade baseados em padronizações voltadas para reduzir as variações na prática médica e eliminar serviços desnecessários. $A$ avaliação da qualidade, nesta perspectiva, está baseada fundamentalmente no estado geral de saúde dos membros do plano e na satisfação do paciente, e não nos indicadores de mortalidade, resultados ou de complicações, que usualmente são utilizados para avaliar os serviços de assistência médica (IGLEHART, 1992:743). No final da década de 80, o managed care se havia constituído na principal linha de defesa na estratégia dos empregadores privados contra o rápido crescimento dos gastos com os seguros-saúde de seus empregados (FRECH \& GINSBURG, 1988:61-3),

Muitas das propostas legislativas para reformar os sistemas de serviços de saúde no mundo, a partir da segunda metade dos 80 , independente das filiações ideológicas, promoveram a expansão da assistência administrada, sobretudo do tipo HMOs.

Existem diversos programas de managed care, ou assistência administrada, mas entre os modelos predominantes estão as Health Maintenance Organizations-HMOs, as Preferred Providers Organizations-PPOs e os chamados point-of-service plan, que é uma versão mais recente.

Vejamos em que se constituem:

Health Maintenance Organization-HMOs: as HMOs vêm gradualmente assumindo uma parte cada vez maior do mercado de seguros nos EUA. São vistas por muitos observadores como uma solução de longo prazo para os problemas dos mercados de serviços de saúde, uma vez que geram maior eficiência, ao mesmo tempo que controlam custos. As vantagens que lhes são atribuídas são tantas que alguns autores norte-americanos advogam as HMOs como solução a ser adotada em vários outros países - mesmo nos países em desenvolvimento (Akin et al., 1987:33, apud ABEL-SMITH, 1988:694). 
O desenvolvimento das HMOs foi encorajado como forma alternativa de prestação de cuidados médicos que possibilitaria acesso e continuidade de cobertura com uma melhor relação custo/efetividade. $O$ acesso e a continuidade são assegurados somente se a HMO garante sua viabilidade financeira, isto é, assegura o equilíbrio de recursos necessários para seu crescimento e sobrevivência, assim como resultados satisfatórios a ponto de sustentar sua existência. Combina, portanto, seguro de assistência médica e mercado de serviços, ou seja, funciona como um grupo de pré-pagamento, contratualmente responsável pela provisão de um pacote de serviços mais ou menos abrangente, com pouco ou nenhum custo adicional para seus membros. Isto significa que se seus filiados utilizam menos serviços do que o contratado inicialmente, a organização lucra; caso contrário, a HMO arca com os custos adicionais. Crescimento e sobrevivência estão, portanto, na dependência do estabelecimento de um adequacio mix de riscos que permita manter a utilização necessária, o que tem importantes implicações gerenciais e na seleção da clientela. Por outro lado, o tamanho da HMO parece fundamental para esse balanço: os autores estimam que o tamanho ideal é de aproximadamente 50.000 membros (CLEMENT, 1995).

Em termos gerais, identificam-se como características das HMOs (ABEL-SMITH, 1988:695-6): a) operam num ambiente competitivo; b) adotam em geral alguma forma de seleção de clientela; c) possuem um painel fixo de profissionais; d) em geral não utilizam a forma de pagamento por unidade de senviço, mas contratam volume de atendimento; e) geralmente atuam com referências, isto é, assistência especializada e internações são pagas apenas quando estritamente autorizadas pelos profissionais do quadro (e aqui está um ponto crucial do managed care - a economia está exatamente no uso restrito dos procedimentos especializados e da atenção hospitalar); e f) ainda que, em termos retóricos, a ênfase esteja posta na prevenção, isto significa apenas priorizar o atendimento ambulatorial e referir ou recusar os casos mais complicados ou mais caros.

Na recente versão norte-americana, as HMOs constituem o resultado mais acabado dos chamados managed care systems (sistemas administrados de assistência médica) e 
uma HMO típica opera com base em pagamentos prospectivos, isto é, os pacientes pagam uma taxa anual, usualmente através de seus empregadores, cujo contrato com uma HMO assegura todo o atendimento necessário, prestado de diversas maneiras.

Os programas de assistência médica administrada tipo HMO são muito diversificados, mas na essência constituem variações em torno de três tipos básicos de organização: o chamado staff model, em que os médicos são contratados como assalariados, diretamente pela $H M O$, para atender à clientela; o modelo de grupo, onde a $H M O$ contrata grandes e/ou pequenas empresas médicas, dependendo da prestação, montando-se uma rede de serviços responsável pelo atendimento dos membros do plano; e o modelo de Independent Practice Association-IPA, em que são contratados profissionais isolados ou pequenos grupos, para atendimento em seus próprios consultórios ou clínicas. Este último modelo foi o que mais cresceu na última década.

Em todos os casos, os contratos são feitos com os profissionais/grupos/empresas a um preço percapita negociado, pago globalmente ou segundo tabelas de preços também definidas previamente. $O$ fato de os médicos serem assalariados ou pagos por um "pacote", e não por unidade de serviço, evita a superutilização e incentiva a responsabilização pelos custos dos serviços.

Com o gerenciamento cada vez mais detalhado das prestações, os conflitos entre os managers e os médicos têm sido freqüentes e, em geral, as revisões e auditorias são feitas por seus pares. Muitas HMOs têm empregado diretores médicos para estas funções, controlando com rigor as quantidades de serviços prestados e selecionando cuidadosamente os profissionais a ela vinculados, segundo as "necessidades" dos seus membros.

Nos sistemas HMOs os médicos de clínica geral atuam como "porta de entrada" para o atendimento pelo plano, isto é, cada membro somente pode ter acesso à assistência especializada através da referência feita por esse profissional. As HMOs asseguram, de fato, o livre acesso à consulta com o clínico geral e mantêm estrito controle sobre a marcação de 
consultas com os especialistas. Muitos planos incorporam incentivos financeiros, negociados com os médicos, para induzir a diminuição das referências aos especialistas, dos pedidos de exames complementares de diagnóstico e das internações. Esta função de contenção da demanda é assumida pelos médicos de forma relutante, pelos conflitos potenciais que provocam, tanto com os pacientes quanto com os colegas especialistas. Esse papel-chave atribuído ao clínico geral nas HMOs difere dos sistemas tradicionais, principalmente pelo fato de ser imposto por rígidos controles gerenciais, estritamente financeiros, e não por uma lógica de organização do sistema de serviços de saúde que privilegie a atenção primária. Ironicamente, os sistemas de HMOs americanos têm tido muita dificuldade de encontrar médicos de clínica geral competentes para esta função, pela própria ênfase histórica colocada na formação especializada.

O crescimento das HMOs entre 1977 e 1988 nos EUA foi espetacular - sua parte no mercado de seguros passou de $2,5 \%$ a $11,5 \%$, respectivamente (FRECH \& GINSBURG, 1988) -, sendo que se considerarmos um período de tempo maior (os últimos 20 anos), é ainda mais impactante: passaram de 30 unidades em 1970, que atendiam a 3 milhões de pessoas, para $230 \mathrm{em} 1980$ (9 milhões de pessoas) e chegou a $700 \mathrm{em} 1988$ (para mais de 29 milhões de pessoas) (Stoline \& Weiner, 1988, apud HAM, ROBINSON \& BENZEVAL, 1990:66). Em meados da década de 1980, muitas delas tiveram problemas financeiros, face aos aumentos nos preços competitivos no mercado, pelo precário gerenciamento financeiro e também pelas medidas de contenção de gastos (públicas e privadas). Por outro lado, tiveram pouco êxito na redução dos gastos sanitários; na realidade essas organizações foram hábeis em reduzir seus próprios custos, diminuindo o tempo de internação e priorizando a atenção ambulatorial, ou mesmo selecionando pacientes, o que não se reflete, porém, nos custos totais da assistência médica, além de que o próprio Estado contratou HMOs para determinados serviços. Ainda que algumas evidências iniciais apontassem que a presença das HMOs no mercado havia baixado os custos dos prestadores em competição, avaliações mais recentes não endossam essa afirmação. Ao contrário, estudos mostram que o grau de penetração das HMOs no mercado de assistência médica 
não tem impacto significativo na redução dos preços hospitalares e do gasto sanitário total (ALTMAN \& RODWIN, 1988:106).

Preferred Providers Organizations-PPO: as PPOs constituem uma forma modificada de HMO, criadas como resposta dos médicos à política empresarial e governamental de estímulo às HMOs. São planos de seguro que oferecem prêmios mais baixos porque negociam descontos com médicos e hospitais específicos, no pagamento por unidade de serviço, em troca de determinado volume de trabalho. Constituídas por contratos entre seguradores (ou outras "terceiras partes"), prestadorés e consumidores, através de negociações sobre alguns termos preferenciais (como menor preço, concordar com revisões especificas etc.), em troca de incentivos financeiros (tais como redução de co-participação do usuário e cobertura adicional de serviços) para favorecer os prestadores da PPO, parte do seu sucesso deve-se ao fato de os pacientes terem mais possibilidade de livre escolha. Em outras palavras, os segurados não são obrigados a consultar-se inicialmente com o clínico geral, os serviços de prestadores externos ao elenco de profissionais da PPO são também cobertos e os prestadores não estão submetidos aos riscos das variações no volume da utilização dos serviços. 0 desenvolvimento das PPOs também foi espantoso, passando de 5 unidades em 1983 para 600 em 1987, atendendo aproximadamente a 31 milhões de pessoas (HAM, ROBINSON \& BENZEVAL, 1990:66). O mecanismo preferencial consiste em utilizar o poder da corporação médica para negociar termos de pagamento mais favoráveis e maior eficiência dos prestadores. Ironicamente, porém, a mudança mais significativa com 0 aparecimento destas novas organizações foi que os financiadores tornaram-se cada.vez mais envolvidos no gerenciamento da prestação de serviços médicos, ou seja, em atividades tipicamente regulatórias (ALTMAN \& RODWIN, 1988:107), contra toda a preocupação não intervencionista da sociedade americana e, principalmente, dos médicos.

Point-of-Service Plan: a diferença essencial em relação aos anteriores está nos incentivos aos pacientes (melhores benefícios, co-pagamentos mais baixos) para canalizarem suas demandas de serviços médicos através dos clínicos gerais, fortalecendo o papel deste 
profissional na contenção da demanda. Por outro lado, embora o plano aceite que o segurado possa optar por consultar um profissional de fora de seu elenco (daí o nome do plano), o paciente deverá pagar uma parte substancialmente alta por tal atendimento.

Os autores enfatizam que o rótulo sob o qual o managed health care opera (HMOs, PPOs ou outros) é menos importante do que as características e estruturas dos planos especíicos e do mercado local no qual eles funcionam. Assim, para terem êxito, as estratégias que se destinam à modificação das práticas dos prestadores devem necessariamente apoiarse em substancial parcela do mercado. A influência da assistência administrada opera em três niveis simultaneamente (HOY, CURTISS \& RICE, 1991:24): a) cada rede de managed care procura impor um padrão de prática às empresas prestadoras e/ou profissionais contratados, incentivando a mudança do perfil próprio de cada prestador e transferindo a "nova cultura organizacional" para os demais participantes da rede de serviços; b) o mercado total de serviços de saúde partilhado, administrado coletivamente por todos os planos de managed care numa comunidade, influencia os padrões de prática dos prestadores (isto é, estabelece padrões de assistência para aquela comunidade); e c) esse mesmo mercado interfere também na possibilidade dos demais planos recrutarem médicos cujo padrão de prática não seja consistente com essa cultura organizacional.

Para atingir esses objetivos, foi desencadeado um processo acelerado de consolidação da indústria de seguros em torno das estratégias de managed care, isto é, as seguradoras passaram das formas tradicionais para a assistência administrada, cujos planos se consolidaram nos mercados locais e regionais, configurando, portanto, uma extraordinária mudança tanto no papel dos seguros tipo managed care, quanto no total dos benefícios de seguro-saúde fornecido pelos empregadores aos seus trabalhadores. Isto significou o desenvolvimento de "produtos" diferenciados oferecidos no mercado de seguros (por exemplo, diferentes pacotes de prestação, com maior ou menor co-participação, possibilidade de livreescolha etc), que provavelmente veio obscurecer a crescente concentração de poder nesse setor (MILLER \& LUFT, 1991:46). 
De qualquer forma, as HMOs norte-americanas não se tornaram altamente competitivas, como se supunha, e dadas as dificuldades financeiras mais recentes, não é absolutamente certo que sobrevivam com tanto vigor como aparentaram nos anos 80 .

\section{Competição: a essência dos modelos de reforma sanitária nos 80}

Em junho de 1977 a Federal Trade Commission organizou em Washington uma conferência sobre "Competition in the Health Care Sector: Past, Present, and Future", para a qual convidou especialistas aos quais foram encomendados estudos específicos sobre o assunto, motivada pelo intenso debate à época sobre como o governo norte-americano deveria atuar para controlar os gastos sanitários?

As palavras-chave eram regulação e competição, colocadas em oposição. Regulação, nessa discussão, se referia ao controle estatal de qualquer espécie, e competição não tinha um significado preciso, mesmo entre os economistas: na assistência médica, era vista como podendo produzir uma enorme variedade de resultados, dependendo da estrutura legislativa e institucional sobre a qual atuava.

A partir dessas discussões, os anos 80 assistiram a uma série de processos de reforma dos sistemas de serviços de assistência médica, onde o discurso retórico sempre esteve centrado na competição (o que tem permanecido nos 90 ), mas o resultado das reformas implementadas com esse viés, perceptível até o presente momento, tem sido de aumento da regulação estatal, uma vez que os mercados, como se sabe, jamais funcionam sem a mão (visível) do Estado.

Coerente com essa tendência, praticamente todas as propostas de reformas dos sistemas de serviços de saúde na Europa advogam a introdução nos sistemas públicos de mecanismos concorrenciais que imitam o jogo de mercado. Duas têm sido particularmente discutidas, constituindo novos modelos paradigmáticos para a área sanitária, sobretudo para as reformas dos sistemas nacionais de saúde: o Mercado Interno (Internal Market) 
implementado na reforma inglesa de 1989/1991, e a Competição Pública (Public Competition), que está sendo estudada e desenvolvida experimentalmente em alguns condados na Suécia. Ambas têm como paradigma a denominada Competição Administrada (Managed Competition) que teve origem nos EUA.

\section{Managed Competition ou "Competição Administrada"}

O termo "competição administrada" (managed competition) foi criado por Alain Enthoven, em documento preparado pelo autor como consultor do governo dos EUA em 1977 (ENTHOVEN, 1978a), difundido após a reunião da Federal Trade Commission, em Washington, e, posteriormente, reelaborado numa proposta de reforma do sistema de saúde norte-americano, baseada no aproveitamento dos mecanismos competitivos e regulatórios existentes no sistema para redirecionar a organização da assistência médica, com participação mista pública e privada (ENTHOVEN \& KRONICK, 1989) ${ }^{8}$.

O conceito de "competição administrada" foi elaborado na primeira formulação dessa proposta ${ }^{9}$, que propunha a criação de

"um sistema nacional de seguro-saúde cuidadosamente modelado e administrado, baseado na idéia da livre escolha por consumidores conscientes [dos preços dos serviços] e na competição de preços entre planos alternativos de financiamento e distribuição de serviços" (ENTHOVEN, 1988:305).

Para este autor, existiriam instrumentos disponíveis aos sistemas de pagamento por terceiros (que nos EUA podem ser empregadores, grupos gerenciadores de serviços de saúde, a Federal Health Care Financing Administration e os governos estaduais) que permitiriam não apenas administrar preços, mas garantir maior cobertura a diferentes clientelas, com melhor qualidade da atenção, e administrar os custos da assistência médica.

Em 1989, na reatualização dessa proposta, Enthoven \& Kronig defendiam a premissa 
de que o sistema sanitário de administração mais simples e efetivo é aquele submetido a um financiamento e gestão unificados e que uma sociedade desenvolvida como a norte-americana não podia se furtar por mais tempo a promover a universalização do direito de acesso aos serviços de saúde a toda população.

$\mathrm{Na}$ base da proposta estava, segundo ENTHOVEN (1988), a distinção entre um mercado livre para o financiamento e distribuição de serviços de saúde - que para ele não permitem alcançar objetivos de eficiência e eqüidade - e a formulação de um sistema de "competição administrada", designado para direcionar o financiamento de um sistema de saúde segundo aqueles objetivos. A intenção era, portanto, tentar utilizar a competição entre as forças de mercado para direcionar os sistema de serviços de saúde na perspectiva da eficiência e da eqüidade.

Argumentava-se que em um mercado livre, composto por consumidores individuais no lado da demanda, sem normas reguladoras e gerenciamento ativo pelos "responsáveis ou patrocinadores" (sponsors), os seguradores estariam liberados para perseguir objetivos de lucro ou sobreviver utilizando várias estratégias competitivas, que destruiriam quaisquer objetivos de eficiência e eqüidade. Essas estratégias incluiriam seleção de riscos preferenciais, segmentação do mercado, diferenciação de produtos com aumento dos custos comparativos, descontinuidade da cobertura, recusa ou exclusão de clientela dependendo de condições de saúde pré-seguro, vezos de informação sobre cobertura ou qualidade e criação de barreiras de acesso.

Para o autor, o sucesso parcial das experiências de competição entre planos de seguro de pré-pagamento (tipo HMOs) evidenciava a disponibilidade de instrumentos para habilitar os sponsors na utilização da competição para superar esses entraves e atender melhor a suas respectivas clientelas. Os responsáveis (sponsors) são definidos como ativos agentes coletivos do lado da demanda, que contratam planos competitivos e continuamente estruturam e ajustam o mercado para superar aquelas tendências "naturais" para a ineqüidade e a ineficiência; ou seja, num modelo competitivo, o responsável funcionaria como um "corretor" 
que estruturaria a cobertura; contrataria com os beneficiários e os planos de saúde segundo regras de participação; gerenciaria o envolvimento dos diversos atores no processo; arrecadaria os prêmios e/ou as contribuições; e administraria os subsídios cruzados entre beneficiários e os incentivos disponíveis para todo o grupo (ENTHOVEN, 1988:307). Nos EUA, estes sponsors poderiam ser os empregadores, as organizações administrativas dos serviços sanitários e de welfare, o r.ealth Care Financing Administration (federal) e os governos estaduais, ou seja, o chamado "terceiro pagador".

A essência da managed competition, para ENTHOVEN (1988), seria a utilização do instrumental disponível para estruturar, a partir do elenco de planos de seguro-saứde existentes, a escolha do consumidor (que não é necessariamente o usuário dos serviços) segundo custos e objetivos de eqüidade e eficiência. Em tal sistema, o mercado não deve ser visto meramente como bilateral (demanda e oferta), mas trilateral, que inclui consumidores, planos de saúde e sponsors.

O objetivo maior da managed competition, no plano teórico, é reconciliar eqüidade e eficiência; e a crença é que um sistema pode ser modelado e organizado de forma a motivar prestadores a perseguir eficiência na alocação de recursos, em grau razoável, e os consumidores a fazer escolhas conscientes quanto ao custo; ao mesmo tempo que são atendidos plenamente em suas necessidades.

As propostas de Enthoven e Kronick para os EUA não obtiveram viabilidade política, mas estimularam a organização dos sponsors contra os prestadores e a regulação (pública e privada), o que resultou na concentração do setor de seguros privados, e têm influenciado de forma importante praticamente todos os processos de reforma fora dos EUA, sobretudo aqueles que se tornaram paradigmáticos e que analisaremos sucintamente a seguir.

O modelo do "Mercado Interno" (Internal Market) ou do Working for Patients (1989/1991) Britânico 
A proposta de Mercado Interno, baseada em mecanismos de contracting out, tem como principal objetivo a separação entre as responsabilidades, de um lado, de financiamento, direção e controle integral do sistema sanitário; e, do outro, de prestação do serviço (em termos sucintos, a separação entre financiamento e provisão, mediada por contratos entre compradores e prestadores). Tem como eixo central o recurso à competição para a seleção dos prestadores que conseguem fornecer um determinado pacote de prestações com uma melhor relação qualidade/preço. A melhor oferta pode ser comprada de um serviço público, de um serviço privado, lucrativo ou não, ou ainda de empresas pertencentes ao setor terciário. O contracting out caracteriza-se como uma versão particular da extensão de mecanismos concorrenciais ao âmbito público e, dependendo do caso, como expansão da oferta privada (GRANAGLIA, 1993:3 e 13).

O recurso a procedimentos competitivos constitui a diferença fundamental entre 0 contracting out e a política de convênios com o setor privado e beneficente, utilizada em muitos sistemas de serviços de saúde (inclusive o brasileiro).

Os objetivos dessa proposta de reforma constituem-se naqueles tradicionalmente associados à privatização: obter maior eficiência técnica e alocativa, isto é, minimização dos custos de produção para determinadas quantidades de bens/serviços; e produção de pacotes quantitativa e qualitativamente mais adequados à livre escolha do consumidor.

O conceito de Mercado Interno foi inicialmente desenvolvido pensando-se na assistência hospitalar, talvez porque a idéia se constrói nas revisões feitas em função da reforma do NHS inglês, onde grande parte da assistência especializada, excluída a atenção primária prestada pelos GPs, é fornecida em um contexto hospitalar (como na Suécia também). A cunhagem do conceito teve a contribuição de ENTHOVEN (1985) mas no contexto da reforma inglesa é bastante mais elaborado, incorporando a experiência anterior da reforma na área educacional. A inclusão dos fornecedores privados faz com se tenha introduzido também a expressão "mercado misto ou de prestadores" ou ainda "competição entre 
prestadores" (HOUSE OF COMMONS, 1989). No debate geral, entretanto, a atenção está centrada nos prestadores públicos, simplesmente porque representam a grande maioria em quase todos os países centrais, com exceção do Canadá e dos EUA.

Adoto aqui a denominação de mercado interno e não contracting out, concordando com FRANCE (1993:37), primeiro porque foi o termo cunhado originalmente para designar tal reforma; e segundo porque capta com mais precisão a intenção de modificar a modalidade até então utilizada pelo Reino Unido para garantia da prestação da assistência médica à sua população.

A essência do conceito está na distinção entre o papel do prestador da assistência médica e o de comprador de senviços (isto é, a separação entre provisão e financiamento), mas ambas as atividades continuam a ser desenvolvidas no âmbito público, ainda que por atores diversos, dai o uso do termo mercado, ou seja, estabelece-se uma situação em que as partes se envolvem em uma relação de troca. O princípio orientador é de que "o dinheiro segue o paciente".

Segundo os defensores do modelo, este mecanismo desencadearia forças concorrenciais através das quais os usuários (isto é, as autoridades sanitárias e não os pacientes, e aqui reside uma diferença importante com o modelo de troca tradicional), ao buscarem comprar prestações médicas específicas, de determinada qualidade e menor preço, induziriam os prestadores a competir entre si em termos de preço e qualidade, com a finalidade de manter ou aumentar sua cota de mercado. A diferença central com o modelo público anterior é a perda da garantia do recurso orçamentário anual, que prescindia, portanto, da capacidade do serviço de atrair pacientes, e a necessidade de "correr atrás" das exigências dos compradores para a obtenção de tais recursos para o seu funcionamento. Ou seja, o que conta passa a ser a capacidade dos hospitais de atrair e satisfazer os pacientes e os médicos clínicos gerais que fazem as prescrições, o que quer dizer que as autoridades sanitárias, ao efetuar a compra de serviços, deverão levar em consideração também estes atores $^{10}$. 
O mercado interno pressupõe também autonomia de ambas as partes envolvidas: autonomia em relação ao uso dos fatores de produção e escolha do elenco de produtos a serem oferecidos pelo hospital; e liberdade de escolha da autoridade sanitária sobre o que comprar e de quem.

Pretende-se com essa metodologia conseguir quatro efeitos principais: redução da ineficiência técnica; introdução dos princípios de economia de escala nos serviços sanitários; redução dos preços dos fatores de produção; melhor qualidade na atenção e maior possibilidade de escolha e de satisfação da demanda (isto é, de lugar, modalidade e tempo de tratamento) (Robinson, 1988, apud FRANCE, 1993:39). A esperança é que a pura e simples ameaça de concorrência induza os hospitais públicos a considerarem com maior atenção questões de qualidade e preço, isto é, a importância crucial reside na liberdade de acesso e saída do mercado. As principais argumentações, a favor e contra, dos benefícios dessa reforma são resumidas a seguir.

Redução da ineficiência técnica: no que concerne a este ponto, a competição é vista como um instrumento capaz de constranger os hospitais a reduzirem seu custo unitário, mas em termos concretos não fica muito claro de que forma um ambiente competitivo possa induzir o manager e os médicos hospitalares a implementarem as medidas necessárias para tal, nem quais são os incentivos que estimulam essa busca. Concordando com diversos outros autores, MAYNARD (1991) sustenta que, de fato, o mercado, gerando as informações necessárias para a troca, origina um círculo virtuoso que assegura o comportamento competitivo, isto é, uma melhor informação é o produto, não um pressuposto da concorrência. E o'estímulo ao gerente para ser melhor informado estaria ligado ao próprio jesempenho do hospital, isto é, contratando o manager por tempo determinado, relativamente breve, e sujeitando a continuidade e/ou renovação contratual ao desempenho do serviço. Quanto aos médicos, a questão é mais problemática, mas existe uma ampla disponibilidade de instrumentos para controlar a utilização de recursos pelos profissionais: elaboração de orçamentos clínicos, auditoria médica, peer review, protocolos padronizados para diagnóstico 
e conduta terapêutica, revisões de utilização, sistemas informativos gerenciais entre outros, que envolvem diretamente o profissional na administração do hospital. O problema é que nenhum desses instrumentos depende da existência da competição para serem implementados e, em geral, devem ser vistos como tentativas, de um lado, de melhorar o gerenciamento do serviço e submeter a atuação dos dirigentes a avaliações permanentes e, de outro, de conjugar a ética e autonomia clínica dos profissionais à alocação mais eficiente dos recursos.

Implantação de economia de escala nos serviços sanitários: a argumentação parte da constatação de que, como as economias de escala são constituídas da redução dos custos unitários atribuíveis ao aumento da capacidade produtiva de uma organização, a eficiência dos serviços sanitários pode ser também relacionada a uma melhor utilização da capacidade instalada existente. Em termos dos serviços hospitalares, isto significaria que, com base na teoria econômica das vantagens comparativas, os serviços se especializariam naquilo que têm melhor desempenho e este processo de especialização comportaria a passagem de recursos de um serviço a outro. Em tese, no médio e longo prazos, todos os hospitais alcançariam um modus operandi com capacidade operacional total, mas vendendo produtos diversos. O que é mais plausivel que aconteça, porém, é um redimensionamento do setor hospitalar, uma vez que nem todos têm igual capacidade de resposta ao desafio concorrencial (com falências, fusões, incorporações, como aliás já vem ocorrendo) e, como resultado, uma capacidade produtiva inutilizada. A questão que permanece, portanto, é se a perda de capital inutilizado seria compensada pelos aumentos na eficiência devidos à especialização e à economia de escala. Por outro lado, o efeito escala não é automático: sua fonte principal é usualmente a substituição da mão-de-obra pelo investimento tecnológico, que, entretanto, na área sanitária não funciona assim, pois que é capital e trabalho intensiva, de forma cumulativa, uma vez que a nova tecnologia não dispensa nem pessoal nem o aval do profissional nuclear e mais caro (o médico), nem tampouco as tecnologias mais baratas. De qualquer forma os médicos deveriam trabalhar em estreita colaboração com os managers, o que por princípio é problemático. 
Redução dos preços dos fatores de produção: em teoria supõe-se que o mercado interno criaria diferenças geográficas, seja em termos de valores salariais, seja em relação às especialidades. Como na maior parte dos serviços sanitários públicos europeus as estruturas salariais são determinadas mediante contratos nacionais, negociados entre o governo e as organizações profissionais e/ou sindicais, a questão que fica em aberto é se o princípio da contratação e controle da força de trabalho em nivel local é aceitável para as organizações profissionais e sindicatos e, possivelmente, os diferenciais salariais destinados a cobrir a falta de determinadas especialidades poderiam vir a ser generalizados e reivindicados. A argumentação recai assim na necessidade de redução do poder compensador do Estado como empregador monopsônico nas negociações salariais, para poder manter abaixo do mercado o valor das remunerações para determinadas especializações e assim conter os gastos totais.

Qualidade da assistência, acessibilidade e livre escolha do paciente: este é um ponto bastante controverso, onde as especulações predominam, quanto mais não seja porque a informação e os indicadores para a avaliação de qualidade são muito mais escassos e complexos, além de que a acessibilidade e a livre escolha do paciente são temáticas estreitamente interrelacionadas com a questão da eqüidade e, portanto, muito mais políticas que gerenciais. A hipótese mais levantada pelos críticos é a de que o mercado interno estimularia um desenvolvimento desequilibrado da prestação da assistência à população, onde atributos sobre a renda e situação geográfica e social do paciente seriam considerações marginais, comprometendo portanto a distribuição equiitativa da assistência médica. No que concerne à livre escolha, os autores concordam que é um dos principais defeitos da proposta, uma vez que a autoridade sanitária - ou melhor, o gerente - é quem decide qual tipo de assistência será prestada e onde, sem qualquer possibilidade de interferência do paciente.

Em termos gerais, o quadro teórico de referência do modelo de mercado interno parece ser mesṃo o da teoria econômica neoclássica, que é baseado na troca bilateral entre fornecedores e consumidores. Porém, como bem analisa FRANCE (1993:56-9), tenta conciliar 
as premissas de dois outros modelos diversos, considerados ambos insuficientes: 0 de mercado, que tem imperfeições pelo problema da assimetria das informações e pelo abuso do poder de agência dos prestadores, além da inerente inequidade social e dificuldades na contenção de gastos; $\mathrm{e}$ o modelo coletivista, que estimula a ineficiência técnica e a indiferença no confronto das preferências dos consumidores. A nova proposta do mercado interno, de um lado, obriga os prestadores a assumir uma atitude competitiva, ao mesmo tempo que reduz o poder dos médicos e aumenta o dos managers; e, de outro, comporta a subtração do papel de consumidor do paciente, que vem a ser atribuído a uma autoridade sanitária, salvaguardando-se assim, os tetos de gasto. Espera-se desta forma resolver os problemas de assimetria das informações e de contenção de custos e, ao mesmo tempo, tutelar a garantia da equuidade na assistência, deixando a cargo da coletividade o financiamento do sistema.

Ainda que pareça engenhosa, essa combinação não resiste a um exame mais cuidadoso, sob o qual resulta ser essa proposta extremamente simplista, pois que parte de pressupostos equivocados na apreensão dos sistemas sanitários e, pelo menos três pontos merecem ser enfatizados (FRANCE, 1993:58-9):

1. por definição os sistemas de saúde não são caracterizados por relações bilaterais de troca, mas sim por uma rede extremamente complexa de interrelações dos mais variados tipos e, nestas conexões de relações, o paciente não é nem independente nem o único a influenciar a demanda; tampouco a autoridade sanitária é tão autônoma a ponto de desempenhar o papel de consumidor no interior do mercado interno e pode querer desfrutar de vantagens potenciais passíveis de serem colocadas por sua posição, que inclui inclusive oportunidades de exercer um poder monopólico ou monopsônico;

2. a formalização da separação dos papéis de financiamento e provisão de serviços através de relações contratuais comporta a desintegração vertical de um serviço sanitário público e o aumento da complexidade sistêmica, ao mesmo tempo que rejeita uma das razões de ser fundamentais dos sistemas sanitários públicos, uma vez que incorpora os problemas correlacionados aos contratos. Ou seja, os defensores do modelo de mercado intemo parecem subestimar a importância dos direitos de propriedade no processo de alocação de recursos; $\boldsymbol{e}$

3. o funcionamento do modelo do mercado interno pressupõe também a redução da 
segurança dos postos de trabalho dos profissionais sanitários; transferência de poder dos médicos para os managers; limitação da liberdade de escolha dos pacientes e dos médicos; descentralização, com diminuição do poder da autoridade central de controlar tanto a distribuição das prestações sanitárias e o nível de capital fixo existente, quanto o nível de endividamento dos serviços, além das escalas salariais e das condições de trabalho dos profissionais. Na medida em que tais mudanças na distribuição dos direitos e dos poderes não sejam possiveis, ou mesmo encontrem fortes resistências, pode acontecer que os efeitos teóricos esperados, positivos e negativos, não se realizem.

Conseqüentemente, a sua viabilidade é uma questão tanto política quanto operacional, uma vez que os modelos teóricos analisados na literatura são muito gerais e devem necessariamente adequar-se à realidade concreta de cada país, refletindo suas características institucionais, legais, econômicas, sócio-políticas e culturais, além dos legados herdados da implementação das políticas anteriores. O modo como é implementado, porém, é extremamente importante, não apenas para a determinação do impacto dos efeitos produzidos, mas também para a avaliação do desmonte real que pode efetivamente produzir tal implementação.

\section{O modelo da Competição Pública (Public Competition) ou da Reforma Sueca}

Segundo seus formuladores, como tipo ideal, o conceito de public competition (competição pública) se refere a uma grande gama de atividades, sendo que o modo como se configura no particular contexto de um sistema sanitário pode variar muito. Entretanto, qualquer componente específico de escolha deve refletir os princípios organizativos básicos de seu modelo ideal, constituído de três componentes:

1.propriedade e gestão pública das instituições prestadoras de serviços;

2. livre escolha do médico e do serviço pelo paciente, de forma diferente do conceito tradicional de livre escolha, porém, uma vez que a seleção dos serviços e profissionais deve restringir-se aos elencos dos institutos e centros existentes numa determinada área e financiados com capital público;

3.flexibilidade orçamentaria, uma vez que requer ajustamentos contínuos e disponibilidade de recursos para incentivos em função de produtividade e eficiência organizativa, que implica ainda reajustamentos anuais na composição do capital e nos fundos para capacidade instalada. 
A public competition se distingue do contracting out pela adoção de um mecanismo competitivo específico, diferente do mercado tradicional, isto é, em vez do shoping around independente do regime de propriedade e da estrutura em que operam os diversos atores, a competição pública relaciona remuneração das diversas organizações prestadoras à capacidade de atrair pacientes (ou seja, à quota de mercado satisfeita) e ao cumprimento de alguns indicadores de resultados, sendo que as instituições prestadoras que participam desse modelo são apenas as de propriedade pública.

Originalmente, o modelo da Public Competition foi formulado por SALTMAN \& von OTTER (1987), tendo como referência as necessidades de mudança no sistema de saúde sueco e, principalmente, como alternativa tanto aos desenvolvimentos do setor privado na última década, impulsionados e defendidos por governos neoliberais, quanto às demandase críticas da população à rigidez dos serviços prestados, ou ao que os autores chamam o "congelamento do sistema de saúde sueco", ou seja a sua falta de flexibilidade.

A pretensão da mudança que se propõe, para um modelo público paradigmático como o sueco, é, por um lado, promover a eficiência interna do sistema através da introdução de incentivos ao estilo daqueles existentes no mercado, mas mantendo a estrutura pública de alocação de recursos; por outro lado, melhorar a capacidade estrutural dos serviços sanitários públicos para satisfazer às múltiplas demandas contrapostas pela população: listas de espera para algumas cirurgias, horas de consulta pouco convenientes, regulamentações complicadas quanto aos serviços onde deve ser realizada a prestação etc.

Nessa perspectiva, é uma proposta voltada para os sistemas públicos de saúde, cujo modelo tem como ponto essencial encorajar os prestadores a usar os recursos públicos disponíveis de forma mais eficiente e efetiva, reforçando a estrutura descentralizada, priorizando a atenção primária, localmente controlada, estimulando, porém, a mudança de ênfase para as atividades de promoção e prevenção. A satisfação e a escolha dos pacientes é o principal objetivo do modelo, relacionadas entretanto, com os objetivos de eqüidade e acesso universal, o que significa retirar do conceito de escolha individual sua relação com o valor de troca. $A$ 
implantação do modelo requereria também substancial flexibilidade dos sindicatos dos profissionais de saúde e dos políticos.

Como modelo conceitual, não engendra uma mudança radical na estrutura dos sistemas de saúde. Ao contrário, sua força central está na preservação dos controles fiscal e de qualidade, tanto quanto da eqüidade. Isto significa basicamente que os orçamentos permanecem globais e prospectivos, com o gasto total para cada setor fixado a priori, além de que os padrões nacionais e o controle de qualidade continuarão conduzidos centralmente pelo governo.

Comparação entre os dois modelos: Competição Pública e Mercado Interno

Ainda que formulados quase que contemporaneamente, partindo do elemento comum de introdução de mecanismos competitivos em sistemas sanitários públicos e compartilhando alguns objetivos (tais como melhoria da eficiência interna na prestação de serviços, utilização mais produtiva de capital, otimização da relação custo-eficácia, transformação da cultura institucional) que configuram uma reforma estratégica, os dois modelos -Mercado Interno e Competição Pública - diferem bastante entre si, segundo SALTMAN \& von OTTER (1991).

O Mercado Interno pretende, teoricamente, reestruturar a responsabilidade decisória de modo a encorajar uma melhor relação entre custo e eficácia em nivel de autoridade local. Isso se conseguiria através da transformação de cada distrito em uma unidade empresarial altamente independente e da atribuição de maior poder ao manager geral do distrito (tal como um Chief Executive Officer de uma empresa privada), do qual se espera que desempenhe as seguintes funções (ENTHOVEN, 1985): controle do orçamento fixo, com possibilidade de redistribuição interna entre serviços; contratação de serviços dentro e fora do distrito, entre um leque de opções público e privado; reformulação de contratos, seja com médicos clínicos gerais seja com especialistas, de modo a rever critérios e fornecer incentivos; negociação em nível local dos salários do pessoal; recolhimento de fundos sobre o mercado de capitais privados; venda de propriedades distritais existentes, se for oportuno. 
Estas medidas reequilibrariam, nas previsões do modelo teórico, as relações existentes entre os elementos de controle centralizado e aqueles de gestão local em um sistema sanitário público. Criando um gerente local influente e com considerável autonomia decisória (e sobretudo dotando-o da faculdade de comprar senviços produzidos seja pública seja privadamente), o enfoque do mercado interno (ou mercado misto) reestruturaria os sistemas sanitários de gestão pública, segundo linhas empresariais descentralizadas, semelhantes àquelas em vigor nas grandes sociedades do setor privado (SALTMAN \& von OTTER, 1991).

Cada um dos modelos é sustentado, porém, por incentivos de mercado fundamentalmente diferentes, conforme a argumentação de SALTMAN \& von OTTER (1991:6970) esquematizada abaixo.

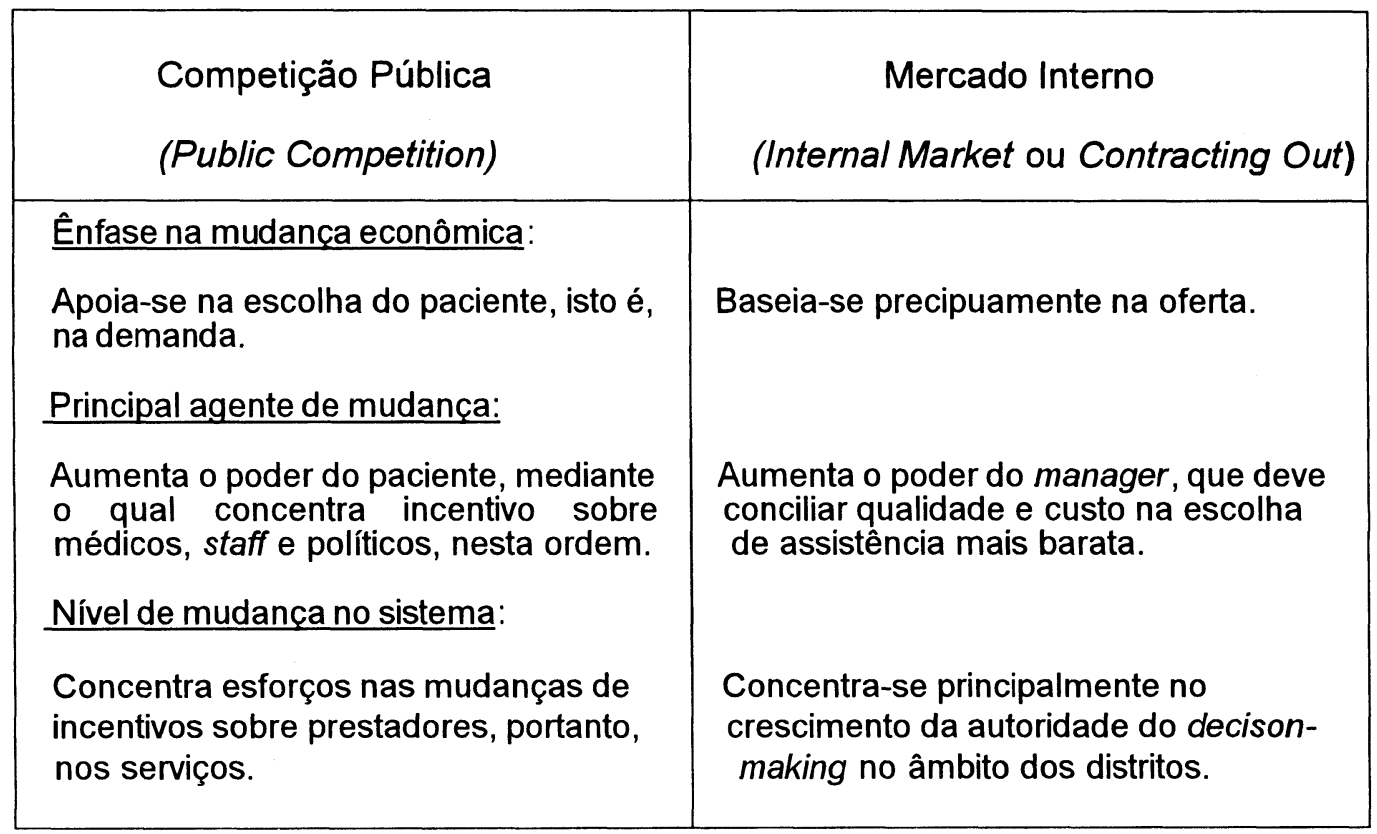

Fonte: SALTMAN \& von OTTER, 1991:70 
Embora seja verdade que os dois modelos respondem a fortes pressões econômicas que emergem nos sistemas sanitários públicos e tenham sido formulados para, no longo prazo, abrir caminho para uma reforma estratégica na estrutura organizativa dos serviços, de fato eles baseiam-se em metodologias conceituais muito diferentes. Ainda que todos os dois tendam a resgatar a gestão pública dos sistemas da prisão do comando burocrático hierárquico, própria de qualquer estrutura administrativa, cada um deles propõe direções diferentes, mesclando diversos ingredientes de mercado e de planejamento, para atingir esses objetivos. Enquanto a competição pública prevê um sistema sanitário de gestão pública no qual a responsabilidade (rigorosa e eletiva) continuará a ser exercitada pelo Estado sobre a produção de serviços, o mercado interno enfatiza a importância de manter um estreito controle do setor público sobre o consumo da assistência. Para SALTMAN \& von OTTER (1991:78), como derivação direta dessa diferença de metodologia econômica, os dois modelos também vêem de forma bastante diversa a questão da eqüidade e igualdade de acesso: enquanto a competição pública mantém a direta responsabilidade pública em termos de eqüidade e de igualdade de acesso, o mercado interno pretende isolar a atividade decisória das influências políticas diretas e dos pacientes.

Sendo assim, estas duas propostas indicariam escolhas políticas diversas no que se refere ao modelo híbrido público/privado que pretendem criar, colocando o acento sobre diferentes incentivos de mercado, sobre diversos protagonistas dos sistemas sanitários e sobre objetivos finais bastantes distintos. E nessa perspectiva, o fato de proporem a introdução de mecanismos de mercado nos sistemas sanitários públicos resulta menos importante do que a sua efetiva implementação, ainda que, no plano teórico, tais propostas estimulem as forças econômicas na direção de diferentes cenários políticos (ou seja, segundo diferentes ideologias) e, como tal, supostamente conduziriam os sistemas onde fossem aplicadas em direções completamente diversas. 


\section{PARA CONCLUIR}

A nova agenda de reforma dos serviços de saúde, que já não é tão nova assim, estava centrada numa "mudança de paradigma" $(O E C D, 1987)$ da intervenção estatal em campo social (BENNETT, 1990:12-21), cujas justificativas eram as mesmas utilizadas para decretar o fim do welfare state, e o elemento central seria a implementação de políticas que se baseavam no conceito de demanda expressa segundo as preferências do consumidor $e$ que levavam em consideração a questão dos custos.

Seus pontos fundamentais eram a eficiência gerencial, responsabilização interna com os gastos dos serviços, resposta às preferências do consumidor e (re)equilíbrio da alocação de recursos entre o governo (nos seus diversos níveis) e o mercado (isto é, descentralização para níveis subnacionais e para o setor privado). Isto significou mudança da ênfase na produção direta de serviços pelo governo para provisão em um ambiente regulatório apropriado, com introdução de mecanismos competitivos que, teoricamente, estimulariam a ação individual, proporcionariam melhor resposta do mercado e das organizações não-lucrativas, e desencadeariam o estreitamento das relações entre os consumidores, os prestadores de serviços e os níveis governamentais, tornando possível a

diminuição da necessidade de coordenação e planejamento, com maior ênfase, por exemplo, em unidades governamentais menores.

A principal questão colocada por essa agenda foi, portanto, a afirmação da inerente ineficiência dos serviços estatais e, como a crise impunha a necessidade inexorável de corte de custos e controle de gastos, o resultado "natural" - argumentava-se - seria o corte daquelas áreas consideradas não apenas como as menos eficientes mas também como frustradoras dos objetivos de atingir uma relação apropriada entre oferta e demanda, ou entre impostos e benefícios, ou ainda entre consumidor e serviços.

Grande parte do direcionamento na reorganização dos serviços de saúde tem sido 
centrado na busca de incentivos empresariais como fator comum das diversas iniciativas de reforma, passando da fase de racionalização fiscal para as tentativas, em nivel retórico, de desenvolver nos sistemas sanitários, "a capacidade de adaptar-se a um entorno mais competitivo e dinâmico" (POULLIER, 1990:21). Na perspectiva de aproveitar o "melhor dos dois mundos" público e privado.

Evidentemente, os problemas que essa ampla agenda pretende enfrentar podem ser metas de qualquer governo, independente da estrutura ideológica. Mas, a meu ver, é preciso desvincular esse elenco de mudanças necessárias da falácia de mudar as fronteiras do Estado.

A avaliação comparativa dessas políticas de reforma(ALMEIDA, 1995) constata que as opções e resultados nacionais variaram muito e que existe uma grande distância entre o discurso ideológico e as políticas implementadas, além de uma clara tensão entre os controles político e financeiro e a operacionalização dos mecanismos de competição nos sistemas de saúde.

A difusão da idéia da competição administrada como um mecanismo apropriado para viabilizar a eficiência, seja nos sistemas competitivos (ou pluralísticos), seja nos sistemas públicos tradicionalmente gerenciados de forma integrada, foi difundida com a hegemonia neoliberal que se consolidou nos anos 80 . Difere completamente da competição aberta de mercado, pois um número menor de atores participa diretamente no estabelecimento das condições das transações a serem negociadas. Difere também do enfoque regulador, uma vez que existem poucas barreiras formais à entrada no mercado e nenhuma capacidade unilateral para estabelecer preços e produtos. Entretanto, procedimentos baseados na competição administrada são freqüentemente compatíveis com fortes políticas regulatórias (IMERSHEIN, ROND \& MATHIS, 1992:983-4), dai a sua aplicabilidade nos sistemas europeus e o especial atrativo que exerceram nas reformas das décadas de 80 .

Com base nessa releitura da competição administrada, evidenciada nas experiências 
européias de reforma sanitária, e em contraponto com o modelo norte-americano, MAYNARD (1996:15) faz uma distinção entre a competição administrada e o que ele conceitua como competição regulada. Esta última seria a que foi implantada na reforma inglesa e estaria restrita ao lado da oferta, com manutenção de uma única fonte financiadora, ao passo que a primeira envolveria ambos lados - da oferta e da demanda - além de comportar diferentes fontes de financiamento. Para este autor, o funcionamento das duas formas de arranjos competitivos nos serviços de assistência médica tem sido muito limitado, tanto pela excessiva centralização de poder quanto pela inadequada regulação - nos sistemas majoritariamente públicos (como no Reino Unido) - e pelos resultados pouco convincentes dessas experiências - nos sistemas fundamentalmente privados (como nos EUA).

De uma maneira geral, identificam-se pelo menos três padrões de transformação estrutural das instituições nos sistemas sanitários europeus majoritariamente públicos (bem sintetizados por SALTMAN, 1994:20-2).

- A primeira é a reconfiguração das instituições públicas, previamente financiadas por orçamentos globais, para atuarem como empresas públicas independentes; ou seja, embora permaneçam de propriedade pública, e mantenham a forma de contabilidade correspondente para seu desempenho, devem atrair mais pacientes (através de contratos negociados e/ou da livre escolha do paciente) para financiar seus gastos.

- A segunda se refere aos pagamentos dos clínicos gerais ou dos prestadores de atenção primária (sobretudo médicos), cuja tendência aponta não mais para o assalariamento pelo Estado (ou pagamento por capitação, que é praticamente a mesma coisa) mas sim para pagamentos através de mecanismos que tentam interrelacionar reembolso e desempenho através de contratos.

- E a terceira diz respeito aos mecanismos que transferem para o controle dos prestadores de atenção primária grande parte dos recursos destinados aos hospitais, seja através dos GPs fund-holding do modelo inglês, seja através dos órgãos governamentais dos condados suecos. Tenta-se dessa forma interrelacionar, supostamente, uma série de objetivos: reduzir as referências desnecessárias, encorajar maior qualidade e menores custos, melhorar a continuidade do atendimento e - na medida que os pacientes podem escolher seus agentes ou seu médico clínico geral para a entrada no sistema - dotar os usuários de alguma interferência no processo de decisão sobre seu atendimento. 
É preciso estar atento, porém, para o fato que essas propostas de flexibilização dos contratos públicos e de transformação dos serviços em empresas de direito privado se, por um lado, poderiam possibilitar maior agilidade gerencial em nível executivo - como se argumenta - por outro lado, poderiam acarretar a perda dos instrumentos de controle estatal que foram mais efetivos para a contenção de custos, como atestam as experiências européias. E essa é a tensão que está posta na implementação dessas propostas de reforma.

Além disso, a idéia simplista da privatização como um instrumento para a ação mais eficiente do governo reedita a dicotomia entre administração e política, desconsiderando importantes questões sobre a responsabilização (accountability), desempenho (performance), coordenação, regulação e controle do uso dos recursos públicos. Em outras palavras, a existência de uma economia mista para a provisão da assistência médica no welfare state, que lhe é estrutural, não deve obscurecer o fato de que as formas de atenção pública e privada diferem completamente entre si (nos objetivos, funcionamento e resultados) e não são, de maneira alguma, intercambiáveis, embora as propostas de reformas dos anos $\mathbf{8 0}$ tentem convencer-nos do contrário.

Ambas as esferas, pública e privada, proporcionam diferentes oportunidades para as escolhas coletivas e individuais e, portanto, o debate se a solução apropriada de um conjunto de problemas (através de determinados instrumentos gerenciais ou administrativos) é pública ou privada envolve a combinação de interesses específicos e compromissos ideológicos. É, portanto, um processo político.

De qualquer forma, ao deslocar a responsabilidade estatal para o mercado, a privatização potencialmente altera a estrutura institucional através da qual os cidadãos normalmente articulam, mediam e promovem seus interesses individuais e coletivos. As conseqüências específicas de tal reestruturação não são as mesmas para todos: alguns grupos, numa arena mais privatizada, encontrariam seus interesses mais claramente definidos e mais prontamente atendidos; outros, seguramente se defrontarão com o oposto. Sendo 
assim, qualquer forma de privatização é um fenômeno intensamente político e, portanto, deve ser analisado como tal, embora muito da literatura, principalmente na área sanitária, tente tratá-la como um problema meramente técnico e gerencial. Por outro lado, não se enfatizam as conseqüências da privatização para as idéias e instituições políticas, além de, pelo contrário, apresentá-la como uma adaptação pragmática de técnicas administrativas bem testadas (no setor privado), ou ainda como um exercício necessário e inevitável decorrente dos ajustes às limitações estruturais.

Nessa perspectiva é que FEIGENBAUM \& HENIG (1993:187-90) argumentam que as formas administrativas e econômicas de privatização, que se multiplicam pelo mundo há quase duas décadas e nas quais se inserem as propostas de introdução da competição, a partir dos EUA, do Reino Unido e da Europa Ocidental, deslocam a atenção das questões fundamentais. Na realidade, em vez de ser uma escolha entre meios (ou instrumentos) para atingir objetivos sociais amplamente reconhecidos, a privatização freqüentemente toma a forma de uma estratégia para realinhar instituições e redefinir o processo decisório, isto é, são estratégias de deslocamento de poder.

$\mathrm{Na}$ avaliação dos processos de reforma em curso, os focos centrais de atenção devem ser as mudanças estruturais na capacidade e responsabilidade do governo e não apenas as variações no financiamento, propriedade, regulação e provisão de serviços. Portanto, o mais importante critério para avaliar as alternativas em pauta é apreender se elas representam substancial e não reversível redução nas responsabilidades do Estado para com os direitos de cidadania e na sua capacidade de regular a transição em curso, impedindo ou não a retirada daquele compromisso histórico.

Sendo assim, analisar os esforços de privatização com base em seu impacto de longo prazo nas responsabilidade e capacidade do Estado consiste em reconhecer a diferença qualitativa entre privatização como um instrumento para melhorar o desempenho governamental, e privatização como um assalto aos fundamentos básicos do welfare state. 
Portanto, essas reformas dos anos 80 , e que continuam nos 90 , foram importantes não apenas por aquilo que mudaram mas também pelo que preservaram (SALTMAN, 1994:22). De um lado, deram maior visibilidade à complexidade dos sistemas sanitários; ressaltaram a importância da gerência, assim como evidenciaram as dificuldades trazidas pelas transposições mecânicas, para a área social, de teses vitoriosas no campo econômico. Do outro, significaram que os mecanismos e incentivos competitivos foram reinterpretados e um setor público fortemente regulador foi o resultado mais imediato dos primeiros anos da implantação dessas reformas. Ou seja, apesar do pouco tempo de implementação das experiências reformistas dos países considerados paradigmáticos (como EUA e Reino Unido) e embora as reformas tenham sido justificadas por uma retórica neoliberal às vezes radical, o resultado visível até o presente momento é paradoxal: o resultado real das políticas de contenção e reforma tem sido de estrito controle estatal (e do setor privado, nos EUA) tanto a macro como a micronível do desempenho dos serviços de saúde e da autonomia profissional. Daí o "paradoxo da intervenção neoliberal", assinalado pelos autores (RUGGIE, 1992; FIORI, 1992, 1993).

Um outro ponto, quase óbvio, que vale a pena ressaltar, refere-se à pclarização dos enfoques de regulação e competição, como resultante de todo o embate político-ideológico que atravessou os anos 80 . Colocados como alternativos um ao outro, e em campos opostos, esses conceitos têm sido utilizados com significados mutuamente exclusivos. Essa visão dual da realidade é contemporânea de outras polarizações - como entre o técnico e o político, entre o Estado e o mercado - colocando falsos dilemas e encobrindo as enormes dificuldades e os grandes desafios que todas essas transformações têm trazido tanto para os policy makers, quanto para os profissionais, técnicos e pesquisadores da área.

A realidade não confirma essas polaridades: via de regra, as estratégias de contenção de custos e de reforma combinam mecanismos regulatórios e competitivos, assim como diversos outros componentes difíceis de classificar, denunciando o indisfarçável vezo ideológico subjacente à aquelas afirmações.

Alguns autores consideram qualquer intervenção estatal como regulação, enquanto 
outros reservam o termo para designar aqueles procedimentos de utilidade pública onde uma agência governamental controla resultados, preços, investimento e desempenho do setor privado. De forma similar, o termo competição tem sido utilizado para significar qualquer política ou procedimento que envolva alguma força de mercado (freqüentemente diferente das usuais, onde o consumidor é o comprador e não necessariamente o que utiliza o serviço), enquanto outros restringem o termo a situações onde as forças de mercado não apenas dominam a cena, mas operam sem qualquer constrangimento regulatório, público ou privado.

A meu ver essas definições são restritivas e não permitem entender ou mesmo avaliar a realidade em curso no atual momento mundial de mudanças. Uma conceituação mais abrangente de regulação iluminaria aspectos importantes da dinâmica setorial pública e privada, possibilitando maior poder explicativo às análises e avaliações dos processos de reforma dos serviços de saúde. $E$, nessa perspectiva, acolhemos o conceito elaborado por LANGE \& REGINI (1987; 1987a), que definem regulação como:

"os diversos modos como um determinado conjunto de atividades ou de relações entre atores é coordenado, os recursos consentâneos são alocados e os conflitos inerentes, reais ou potenciais, são estruturados" (LANGE \& REGINI, 1987:13).

Este conceito de regulação interrelaciona, portanto, três dimensões-chave: coordenação de atividades, alocação de recursos e administração de conflitos (seja no setor público ou no privado). A interconexão dessas variáveis, através da rede de agentes e atores que integram a arena sanitária, é que determina a governabilidade dos sistemas sanitários.

Assim, a propriedade estatal dos serviços de saúde ou o tamanho do setor público em si não é uma variável especialmente crítica. Na realidade, a capacidade/habilidade do governo de regular diretamente as diversas partes do setor saúde (com seus diferentes fatores de produção) é que é crítica, tanto para o planejamento quanto para a eficiência e a efetividade na distribuição da assistência médica, com maior cobertura e a um custo determinado. Por outro lado, isto não implica, necessariamente, em comando centralizado 
ou autoritário, nem tampouco em absoluta predominância do setor público. Mas implica, sem dúvida, na (re)afirmação da responsabilidade estatal pela adequada assistência à saúde dos cidadãos e das populaçס̃es, seja essa assistência prestada por serviços estatais ou privados.

A diversidade, a segmentação, inerentes aos sistemas sanitários e construídas historicamente, não significam necessariamente fragmentação e ineqüidade, mas denunciam ser imprescindível a regulação (vista como a definimos), sustentada por diretrizes claras que se apoiem em princípios de eqüidade e de solidariedade. Aliás, tão em baixa no mundo de hoje.

E este é o problema central, fundamentalmente político na sua origem, que está presente em todos os processos de reforma. Em muitos casos, isto pode significar aumento de recursos e de estruturas gerenciais, isto é, aumento de gastos, o que, supostamente contraria frontalmente todas as justificativas das reformas propostas.

O lado positivo desse debate e os principais resultados, até o momento, das políticas de reforma implementadas, nos países centrais, não são econômicos, ainda que na maioria dos países, exceto nos EUA, de fato se conseguiu diminuir o ritmo de crescimento do gasto sanitário, em alguns casos com efetiva contenção.

O desafio que está posto nesse amplo movimento de mudanças está dado pela própria implementação das políticas de reforma, que, por definição, são transitórias, pois que transformam a própria política com os resultados às vezes inadvertidos pelos seus formuladores. Numa visão otimista, trazem para a agenda a questão da qualidade da atenção: a importância da avaliação tecnológica, da eliminação do desperdício, da consideração do respeito ao paciente, da revisão do significado do espaço público na prestação de serviços de saúde, sejam eles estatais ou privados. Ou seja, dimensões que parece que se perderam, no padrão de práticas centrado na distribuição tecnológica e no desenvolvimento frenético das especializações cada vez mais fragmentadas, estimulado e desenvolvido no pós-guerras, 
sob a hegemonia norte-americana, e cuja recuperação envolve árduo trabalho dialético de desconstrução e reconstrução, com participação ativa de todos os atores envolvidos no processo, principalmente os profissionais.

Por outro lado, a necessidade de contenção e redirecionamento do gasto hospitalar abre a oportunidade de revalorização das práticas extra-hospitalares e de saúde pública, com especial ênfase na atenção primária, com seus componentes de assistência integral e de intersetorialidade. Porém, a recuperação dessa bandeira política exige revisão da proposta de atenção primária e a sua reinserção no contexto atual de reforma dos complexos sistemas de serviços de saúde, espaço político que a OMS vem tentando reanimar na disputa aberta, também na arena internacional, pelo comando/coordenação dessas políticas de reforma em nível mundial.

Na realidade, para onde caminha essa transição no setor saúde é ainda uma questão em aberto. Embora essas tendências não queiram dizer adesão pura e simples ao mercado, nem privatização sumária, como advoga o discurso ideológico, as medidas de reforma implementadas, em todos os países, estão de fato alterando a organização e o funcionamento dos sistemas de serviços de saúde.

\section{REFERÊNCLAS BIBLIOGRÁFICAS}

ABEL-SMITH, B. The rise and decline of the early HMOs: some international experiences. Milbank Q., 66:694-719, 1988.

ALMEIDA, C. M. As reformas sanitárias dos anos 80 : crise ou transição? Rio de Janeiro. [Tese de Doutorado - Escola Nacional de Saúde Pública] 1995.

ALTMAN, S. H. \& RODWIN, A. Halfway competitive markets and ineffective regulation: the american health care system. In: W. Greenberg, Ed., Competition in the health care sector: ten years later. Durham, Duke University Press, 1988.

BARILETTI, A. \& ARCANGELI, L. La Sanità nel 1987. Queste Istituzione, U.S.P.I., 1987. 
BENNETT, R. J. Decentralization, intergovernamental relations and markets: towards a postwelfare agenda? In: R. J. Bennett, Ed., Decentralization local government and markets towards a post-welfare agenda. New York, Clarendon Press Oxford, 1990.

CLEMENT, G. HMO survival: determination of optimal size. Health serv. reas., 8:10-22, 1995.

ENTHOVEN, A. \& KRONICK, R. A consumer-choice health plan for the 1990s. New Eng. J. Med., 320:29-37, 1989.

ENTHOVEN, A. \& KRONICK, R. Managed competition of alternative delivery systems. In: Greenberg, W., Ed., Competition in the health care sector: ten years later. Durham, Duke University Press, 1988.

ENTHOVEN, A. \& KRONICK, R. Reflections on the management of the National Health Service. London: The Nuffield Provincial Hospitals Trust, 1985.

ENTHOVEN, A. \& KRONICK, R. Consumer-choice health plan. Parte I: Inflation and inequity in health care today: alternatives for cost control and an analysis of proposals for national health insurance. New Eng. J. Med., 298:650-58, 1978a.

ENTHOVEN, A. \& KRONICK, R. Consumer-choice of health plan: a national-health-insurance proposal based on regulated competition in the private sector. New Eng. J. Med., 298:709$20,1978 b$.

FEIGENBAUM, H. B. \& HENIG, J. R. The political underpinnings of privatization. World Politics, (45), 1993.

FIORI, J. L. O paradoxo político da reforma liberal. Lua Nova, (25), 1992.

FIORI, J. L. Ajuste, transição e governabilidade: o enigma brasileiro. In: Tavares, M. da C. \& Fiori, J. L., (Des)ajuste global e Modernização Conservadora. São Paulo, Paz e Terra, 1993.

FRANCE, G. Mercati interni nel settore ospedaliero. In: Elena Granaglia (a cura di), Privatizzacione e Servizio Sanitario Nazionale. Alcune Riflessione a proposito dei mercati inteni, Politeia (Centro per la richerca e la formazione in politica ed etica), N.56:35-80, 1993.

FRECH, H.E. \& GINSBURG, B. Competition among health insurers revisited. In: Greenberg, W., Ed., Competitioin in the health care sector: ten years later. Durham, Duke University Press, 1988. 
GRANAGLIA, E. Introduzione. In: Elena Granaglia (a cura di), Privatizzacione e Servizio Sanitario Nazionale. Alcune Riflessione a proposito dei mercati inteni, Politeia (Centro per la richerca e la formazione in politica ed etica). 56:3-9, 1993.

HAM, C.; ROBINSON, R. \& BEZEVAL, M. Health check: health care reforms in an intemational context. London, Kings Fund Institute, 1990.

HOUSE OF COMMONS Organising health service provision: drawing on experience. London, Select Commitee on Social Services, 1989. [mimeografado]

HOY, E. W.; CURTIS, R. E. \& RICE, T. Change and growth in managed care. Health Affairs, (Winter): 19-26, 1991.

IGLEHART, J. K. The american health care system: introduction. New Eng. J. Med. , 326:9627, 1992a.

IGLEHART, J. K. The american health care system: private insurance. New Eng. J. Med., $326: 1715-20,1992 b$.

IGLEHART, J. K. The american health care system: managed care. New Eng. J. Med., $327: 742-47,1992 \mathrm{c}$.

IMERSHEIN, A. W.; ROND, P. C. \& MATHIS, M. Restructuring patterns of elite dominance and the formation of state policy in health care. Am. J. Sociol., 4:970-93, 1992.

LANGE, P. REGINI, M. Stato e Regolazione Sociale - Nuove prospettive sul caso italiano. Bologna: II Mulino, 1987.

"Regolazione sociale e politiche pubbliche: schemi analitici per lo studio del caso italiano". Stato e Mercato, 19:97-121, 1987.

MAJNONI D'NTIGNANO, B. Analyse des derniers développements et des reformes en matière de financement des systèmes de santé. Rev. Int. Sécurité Soc., 44(3):5-21, 1991.

MAYNARD, A. Health care reform: the role of health economics in informing difficult choices. [Trabalho apresentado no Seminário Internacional - "Tópicos Conceituais e Metodológicos de Economia da Saúde", ENSP/FIOCRUZ, Rio de Janeiro, 1996]

MAYNARD, A. Can competition enhance efficiency in health care? Lessons from the reform of the U. K. National Health Service. Soc. Sci. Med., 39:1433-45, 1994.

MAYNARD, A. Developing the health care market. Economic J., 101:1277-286, 1991. 
MILLER, R. H. \& LUFT, H. S. Diversity and transition in health insurance plans. Health Affairs, (Winter):37-47, 1991.

OECD. Financing and delivering health care: a comparative analysis of the OECD countries. Soc. Policy Stud., (4), 1987.

POULLIER, J. P. El afan por la eficiencia. Rev. Econ. - Reformas Sanitarias Actuales, (681682):7-26, 1990.

RUGGIE, M. The paradox of liberal intervention: health policy and the american welfare state. Am. J. Sociol., 97:919-44, 1992.

SALTMAN, R. B. , The Role of Competitive Incentives in Recent Reforms of Northern European Health Systems. In: International Conference on "Health Care Cost Control: IONternal Market Mechanism", 15-16 May, Quebéc. Mimeo.

SALTMAN, R. B. \& von OTTER, C. , Saggi sulla teoria della competizione pubblica nel settore della sanitá. Roma, Formez, 1991.

SALTMAN, R. B. \& von OTTER, C. Public competition versus mixed markets: an analytic comparison. Health Policy, 11: 43-55, 1989.

SALTMAN, R. B. \& von OTTER, C. Re-vitalizing public health care systems: a proposal for public competition in Sweden. Health Policy, 7:21-40, 1987.

SCHIEBER, G. J. \& POULLIER, J. P. Perspective. Health Affairs, (Fall):199-201, 1991.

\begin{abstract}
Summary: This article analyses the main sanitary reform models in the central countries dissecting the body of ideas that framed the strategies of change and the constituent elements of a new post-welfare agenda also for the health sector. It takes the premise that the fiscal crises of the state as of mid 70' together with the decade's neoliberal hegemony contributed to the formulation of both a common sectorial diagnosis and prescriptions that were disseminated as alternatives for the control of sanitary expenditure increase control and for the functioning of more efficient consumer geared health services. The re-introduction of competition in the health area based on the North-American experience had various re-readings and applications in the European context. In this process some models considered paradigmatic for the necessary re-constructing of health services were created. These were linked to both the macro-economic cost reduction and public deficit growth control demands. The comparative evaluation of such policies in the central countries ascertains that the national options varied a lot and that there is a great distance between the ideological discourse and the implemented policies. It is evident that there is a more central and regulatory state action beside the clear tension between the political and financial controls and the operationalisation of the competition mechanism in the health system.
\end{abstract}

Key words: managed care; managed competition, internal market 


\section{NOTAS}

1 Para uma discussão mais detalhada da crise Sanitária dos 70 , da crise dos serviços de saúde e das tendências de reforma sanitária nos 80 , através da análise dos processos em curso em seis países - EUA, Reino Unido, Alemanha Ocidental, Suécia, considerados paradigmáticos; além de Itália e Espanha, analisados como reformas tardias - ver Celia $\mathrm{M}$. Almeida (1995), As Reformas Sanitárias dos Anos 80: Crise ou Transição?, Tese de Doutorado, ENSP/FIOCRUZ (mimeo).

2 Ver a respeito Economic Policy, 1988, "Special Issue on The Conservative Revolution", Cambridge: Cambridge University Press.

${ }^{3}$ Esse diagnóstico sobre os problemas setoriais pode ser encontrado em Campos (1989) "Crise econômica e Políticas Sociais - Perspectiva Européia", Seminário Nacional sobre Economia e Financiamento do Setor Saúde, Escola Nacional de Saúde Pública/FIOCRUZ, 5-9 junho,1989 (mimeo); Contandriopoulos \& Pouvourville (1991), "Entre Construtivisme et Libéralisme: la Recherche d'une Troisiéme Voie". Séminaire International “La régulation des systèmes de santé: quels modèles et quels outils?, École Nationale de Santé Publique, Rennes 12-14 juin 1991 (mimeo); Diderichsen (1982), "Ideologie in the Swedish health sector today: the crisis of the social democracy". International Journal of Health Service. V. 12(2): 191-200; Gough (1979), The Political Economy of the Welfare State. London: Macmillan; Maynard (1982), "The Regulation of Public and Private Health Care Markets". In: The Public and Private Mix for Health - The Relevance and Effects of Changes, London: The Nuffield Provincial Hospital Trust; McLachlan \& Maynard (1982), "The Public-Private Mix for Health: the Emerging Lessons". In: The Public and Private Mix for Healtth - The Relevance and Effects of Changes. London: The Nuffield Provincial Hospital Trust; Médici (1990), "Incentivos Governamentais ao Setor Privado em Saúde no Brasil”. Relatórios Técnicos, N.2(91), Rio de Janeiro: ENCE/BGE e (1991), "Financiamento e Contenção de Custos nas Políticas de Saúde: Tendências Atuais e Perspectivas Futuras". In. Planejamento e Políticas Públicas. (4):8398; Poulier (1990), citado na bibliografia, entre outros.

4 AJan Maynard (1996:15) afirma que a reforma holandesa foi projetada de forma independente, sem influências externas. Na realidade nos referimos aqui à difusão de idéias e paradigmas e não apenas à participação direta de analistas norte-americanos no processo de formulação das propostas de reforma, como ocorreu, por exemplo, no caso da reforma britânica. E, nessa perspectiva, a Holanda adota as idéias da competição administrada.

${ }^{5} \mathrm{O}$ fenômeno do free-rider foi analisado por Mancur Olson (1965), The Logic of Collective Action, Harvard University Press, e se refere ao fato de que o indivíduo racional pode não se dispor a submeter-se a determinada prática ou pagar por um bem público, uma vez que lhe é possibilitado beneficiar-se de seu aprovisionamento sem dar sua contribuição, "aproveitandose", assim, do esforço alheio, maximizando sua utilidade individual. Um exemplo concreto na área de saúde seria aquele indivíduo que não paga sua contribuição (ou frauda a seguridade social) mas se beneficia, mesmo assim, dos serviços porque os outros pagam. Uma outra dimensão desse procedimento se refere ao indivíduo que se nega a proporcionar o bem público ao free rider, recusando-se a pagar por ele, justificando, assim, sua não contribuição, 
definido como o "dilema do samaritano", conceito econômico, formulado por Steven Brans (1980), Bibliogames - A strategic analysis of stories in the old testament, que diz respeito à competitividade entre os jogadores na lógica racional.

${ }^{6}$ Os planos de pré-pagamento nos EUA começaram a se expandir, discretamente, apenas nos anos 40, sob três formas diversas: as cooperativas de saúde; os planos de segurosaúde (cujo exemplo mais expressivo é o Health Insurance Plan-HIP, da cidade de New York); e os panos promovidos por empresas, como o da Kaiser, que era o único administrado nos moldes do managed care. Sobre o aparecimento, limites da prática e desenvolvimento da assistência médica de grupo de pré-pagamento no EUA e, especialmente, sobre a experiência da Kaiser e dos HIP, ver Paul Starr, La transformación social de la medicina en Ios Estados Unidos de América, México: Biblioteca de la Salud/Fondo de Cultura Económica (1982: 375-82), entre outros.

${ }^{7}$ Os principais textos dessa Conferência (em número de 10) e as discussões de seus doze seletos participantes foram publicados em 1978. Uma década depois, em 1987, dez dos convidados, que escreveram sete dos textos de 1977, foram convocados para fazer uma revisão de suas idéias, com base na avaliação da implementação dos mecanismos de competição. Esta última produção foi publicada no livro Competition in the Health Care Sector: Ten Years Later, Warren Greenberg (Ed.), Duke University Press, Durham and London, 1988, assim como num número especial da revista Journal of Health Politics, Policy and Law, do mesmo ano.

${ }^{8}$ Alain C. Enthoven é um economista americano, filho de pais ingleses, da Business School da Universidade de Stanford, e seu modelo competitivo de seguro nacional de saúde para os EUA inspirou também o programa democrata do Senador Kennedy, no fim dos anos 70. Ainda que sua proposta de reforma não tenha vingado nos EUA, suas teses adquiriram muita força, porque foram consideradas o enunciado mais avançado de um enfoque "de mercado" na política de saúde, que permitia, ao mesmo tempo, maior equidade e melhor qualidade na atenção, como argumentava o autor. Embora não tenha conseguido respaldo político para implementar essa reforma em sua terra natal, Enthoven tornou-se um dos principais mentores e formuladores de propostas de introdução de elementos de competição de mercado nos sistemas de serviços de saúde, tendo colaborado, por exemplo, para a formulação da reforma do sistema inglês, no final dos anos 80 . Ver a respeito: Alain C. Enthoven (1985), Reflections on the management of the National Health Service. London: the Nuffield Provincial Hospital Trust; Alain C. Enthoven (1991), "Internal market reform of the British National Health Service". Health Affairs, Fall (1991): 60-70.

${ }^{9}$ Ver a respeito, ALAIN C. ENTHOVEN (1980), Health Plan: The Only Pratical Solution to Soaring Health Costs, Reading, Massachusetts: Addison-Wesley; ALAIN C. ENTHOVEN (1978a), "Consumer-choice health plan (Parte I) - Inflation and Inequity in Health Care Today: Alternatives for Cost Control and an Analysis of Proposals for National Health Insurance", New England Joumal of Medicine , 298(12):650-58; ALAIN C. ENTHOVEN (1978b), "Consumerchoice health plan (Parte I) - A National-Health-Insurance Proposal Based on Regulated Competition in the Private Sector", New England Journal of Medicine, 298(13):709-20; e ALAIN C. ENTHOVEN (1978c), "Shattuck Lecture - Cutting Cost without Cutting the Quality of Care", New England Journal of Medicine, 298(22): 1229-38. 
${ }^{10}$ Neste ponto os modelos de mercado interno variam segundo as possibilidades de escolha dos pacientes e dos seus médicos. ENTHOVEN (1985) propõe que os pacientes possam ter acesso a qualquer prestador existente no mercado, desde que contratados ou pelo médico geral (ou de atenção primária) ou pela autoridade local, isto é, os compradores adquiririam serviços em qualquer parte do país; outros modelos limitam a possibilidade de escolha do paciente a aqueles prestadores aprovados pela concorrência estabelecida pela autoridade pública; na reforma inglesa (House of Commons, 1989) propõe-se limitar a possibilidade de escolha do paciente aos médicos de atenção primária que têm contrato com as autoridades sanitárias, que, por sua vez, podem prescrever prestações apenas para os serviços que venceram a concorrência com as autoridades sanitárias, isto é, já contratados (FRANCE, 1993:38). 